\title{
Cellular and behavioral effects of altered Nav1.2 sodium channel ion permeability in $\operatorname{Scn} 2 a^{K 1422 E}$ mice
}

\section{Abbreviated Title: Mixed effects on Nav1.2 function in $\operatorname{Scn} 2 a^{K 1422 E}$ mice}

Dennis M. Echevarria-Cooper ${ }^{1,3}$, Nicole A. Hawkins ${ }^{1}$, Sunita N. Misra ${ }^{1,2,4}$, Alexandra Huffman ${ }^{1}$, Tyler Thaxton ${ }^{1}$, Christopher H. Thompson ${ }^{1}$, Roy Ben-Shalom ${ }^{6}$, Andrew D. Nelson ${ }^{6}$, Anna M. Lipkin $^{5,6}$, Alfred L. George Jr., ${ }^{1,3}$, Kevin J. Bender ${ }^{6}$, *Jennifer A. Kearney ${ }^{1,3}$

Departments of Pharmacology ${ }^{1}$ and Pediatrics ${ }^{2}$, Northwestern University Feinberg School of Medicine; Chicago, IL, USA 60611

${ }^{3}$ Northwestern University Interdepartmental Neuroscience Program, Northwestern University, Chicago, IL, USA, 60611

${ }^{4}$ Ann \& Robert H. Lurie Children's Hospital of Chicago, Chicago, IL, USA 60611

${ }^{5}$ Neuroscience Graduate Program, University of California, San Francisco, CA, USA 94158

${ }^{6}$ Department of Neurology, Kavli Institute for Fundamental Neuroscience, Weill Institute for Neurosciences, University of California, San Francisco, CA, USA 94158

*Corresponding Author:

jennifer.kearney@,northwestern.edu

Number of Pages: $\quad 56$

Number of Figures: $\quad 10$

Number of Tables: 2

Number of Words - Abstract: 250

Number of Words - Introduction: 573

Number of Words - Discussion: 1500

Conflict of Interest Statement: ALG receives grant support from Tevard Biosciences, Inc. and is a paid consultant for Praxis Precision Medicines, Inc. JAK serves on the scientific advisory board of the FamilieSCN2A foundation and receives grant support from Praxis Precision Medicines, Inc. The remaining authors declare no competing interests.

Acknowledgements: The genetically engineered mice were generated with the assistance of Lynn Doglio in the Northwestern University Transgenic and Targeted Mutagenesis Laboratory. This work was supported by grants NIH R21 OD025330 (JAK), NIH U54 NS108874 (ALG and JAK), SFARI 629287 and 513133 (KJB); NIH R01 MH125978 (KJB); NSF 1650113 (AML); NIH F32 MH125536 (ADN); NIH KL2TR001424 (SNM); Epilepsy Foundation of Greater Chicago Rovner Fellowship (SNM); FamileSCN2A Action Potential Grant (SNM). 


\begin{abstract}
Genetic variants in $S C N 2 A$, encoding the Nav1.2 voltage-gated sodium channel, are associated with a range of neurodevelopmental disorders with overlapping phenotypes. Some variants fit into a framework wherein gain-of-function missense variants that increase neuronal excitability lead to infantile epileptic encephalopathy, while loss-of-function variants that reduce neuronal excitability lead to developmental delay and/or autism spectrum disorder with or without comorbid seizures. One unique case less easily classified using this binary paradigm is the de novo missense variant $S C N 2 A$ p.K1422E, associated with infant-onset developmental delay, infantile spasms, and features of autism spectrum disorder. Prior structure-function studies demonstrated that $\mathrm{K} 1422 \mathrm{E}$ substitution alters ion selectivity of Nav1.2, conferring $\mathrm{Ca}^{2+}$ permeability, lowering overall conductance, and conferring resistance to tetrodotoxin (TTX). Based on heterologous expression of K1422E, we developed a compartmental neuron model that predicted mixed effects on channel function and neuronal activity. We also generated $\operatorname{Scn} 2 a^{K 1422 E}$ mice and characterized effects on neurons and neurological/neurobehavioral phenotypes. Dissociated neurons from heterozygous $S c n 2 a^{K 1422 E /+}$ mice exhibited a novel TTX-resistant current with a reversal potential consistent with mixed ion permeation. Cortical slice recordings from $\operatorname{Scn} 2 a^{K 1442 E /+}$ tissue demonstrated impaired action potential initiation and larger $\mathrm{Ca}^{2+}$ transients at the axon initial segment during the rising phase of the action potential, suggesting mixed effects on channel function. $S c n 2 a^{K 1422 E /+}$ mice exhibited rare spontaneous seizures, interictal EEG abnormalities, altered response to induced seizures, reduced anxiety-like behavior and alterations in olfactory-guided social behavior. Overall, $S c n 2 a^{K 1422 E /+}$ mice present with phenotypes similar yet distinct from $\operatorname{Scn} 2 a$ knockout models, consistent with mixed effects of K1422E on Nav1.2 channel function.
\end{abstract}




\section{Significance Statement}

The early-onset epilepsy variant SCN2A-p.K1422E displays unique biophysical properties in vitro. To model the impact of this rare variant, we generated Scn $2 a^{K 1422 E}$ mice. Neurons from heterozygous $\operatorname{Scn} 2 a^{K 1422 E /+}$ mice showed functional deficits similar to the loss-of-function effects observed in the Scn2a haploinsufficiency model, as well as gain-of-function effects specific to the K1422E variant. There is also some overlap in neurobehavioral phenotypes between $\operatorname{Scn} 2 a^{K 1422 E /+}$ and Scn $2 a$ haploinsufficient mice. However, Scn $2 a^{K 1422 E /+}$ mice exhibited unique epilepsy-related phenotypes, including epileptiform events and seizures. $S c n 2 a^{K 1422 E /+}$ mice serve as a useful platform to investigate phenotypic complexity of $S C N 2 A$-associated disorders. 


\section{Introduction}

Pathogenic variants in $S C N 2 A$, which encodes the voltage-gated sodium channel Nav1.2 expressed in central nervous system neurons, is a major risk factor for neurodevelopmental disorders (NDD). Within the ion-conducting pore domain of Nav1.2 are four critical residues (Asp-Glu-Lys-Ala or DEKA) that confer selectivity for sodium over all other cations (Dudev and Lim, 2014; Sanders et al., 2018) To date, more than 250 heterozygous genetic variants in SCN2A have been described in a wide range of NDD (Sanders et al., 2018). Severe gain-of-function (GoF) missense variants, resulting in increased neuronal excitability, lead to infantile epileptic encephalopathy, including Ohtahara syndrome and West syndrome (Ogiwara et al., 2009; Wolff et al., 2017, 2019; Thompson et al., 2020). Less dramatic GoF missense variants lead to benign infantile seizures, which resolve before 2 years-of-age without apparent long-term neurological sequelae (Scalmani et al., 2006; Ben-Shalom et al., 2017). By contrast, loss-of-function (LoF) missense variants and protein-truncating variants (PTVs) that reduce neuronal excitability early in development and synaptic plasticity later in development lead to autism spectrum disorder (ASD) and/or developmental delay (Sanders et al., 2012; Ben-Shalom et al., 2017; Spratt et al., 2019). Some of these cases have co-morbid seizures starting later in life, typically months after onset of encephalopathy associated with GoF variants (Wolff et al., 2017).

While many cases fit neatly into this GoF or LoF paradigm, there are numerous cases that do not, particularly those with seizure onset around one year-of-age (Wolff et al., 2017; Berecki et al., 2018; Sanders et al., 2018). One biophysically remarkable example is the de novo missense variant SCN2A-p.K1422E, which disrupts one of the four amino acids that constitute the ion selectivity filter (Figure 1A). This variant alters the overall charge of the selectivity filter, converting the positively charged amino acid, lysine $(\mathrm{K})$, to the negatively charged amino acid 
glutamate (E). The resultant channel, which has been studied in heterologous expression systems, loses sodium selectively, instead becoming a mixed, nonselective cation channel with apparent permeability for sodium, potassium, and calcium with diminished overall conductance (Heinemann et al., 1992; Schlief et al., 1996). Furthermore, the K1422E variant prevents binding of the neuronal sodium channel antagonists tetrodotoxin (TTX) and saxitoxin that bind to the outer vestibule (Terlau et al., 1991; Fozzard and Lipkind, 2010).

To our knowledge, K1422E is the only variant within the existing SCN2A patient population that affects ion selectivity, contrasting markedly with other variants that commonly alter voltage dependence, kinetics, or trafficking (Ben-Shalom et al., 2017; Sanders et al., 2018; Wolff et al., 2019; Adney et al., 2020; Thompson et al., 2020). Given the unique properties of $\mathrm{K} 1422 \mathrm{E}$, it is difficult to hypothesize whether it affects neuronal function in a manner similar to variants that result in gain or loss of function. To investigate this, we generated a mouse model carrying the SCN2A-p.K1422E variant and examined effects on cellular and network excitability using electrophysiological and imaging techniques. Excitatory neurons in allocortex and neocortex exhibited features indicative of functional K1422E-containing Nav1.2 channels, including the presence of a novel TTX-insensitive current and aberrant calcium influx occurring during the Navmediated rising phase of the action potential. Analysis of behaving animals revealed a mix of phenotypes, including infrequent spontaneous seizures, reduced anxiety-like behavior, and alterations in olfactory-guided social behavior. Thus, these data suggest that altering Nav1.2 ion selectivity results in cellular and behavioral phenotypes that partially mirror those observed in other models of Scn $2 a$ dysfunction, in addition to features that are entirely unique to K1422E. 


\section{Materials and Methods}

Heterologous cell electrophysiology. Heterologous expression of human Nav1.2 WT (Addgene \#162279)(DeKeyser et al., 2021) or K1422E was performed in HEK293T cells. Cells were grown in $5 \% \mathrm{CO}_{2}$ at $37^{\circ} \mathrm{C}$ in Dulbecco modified Eagle's medium supplemented with $10 \%$ fetal bovine serum, $2 \mathrm{mM}$ L-glutamine, 50 units $/ \mathrm{ml}$ penicillin, and $50 \mu \mathrm{g} / \mathrm{ml}$ streptomycin. Cells were transiently co-transfected with Nav1.2 and the accessory $\beta_{1}$ and $\beta_{2}$ subunits $(2 \mu \mathrm{g}$ total plasmid DNA was transfected with a cDNA ratio of 10:1:1 for Nav1.2: $\beta_{1}: \beta_{2}$ subunits) using Qiagen SuperFect reagent (Qiagen, Valencia, CA, U.S.A.). Human $\beta_{1}$ and $\beta_{2}$ cDNAs were cloned into plasmids encoding the CD8 receptor $\left(\mathrm{CD} 8\right.$-IRES-h $\left.\beta_{1}\right)$ or enhanced green fluorescent protein (EGFP) (EFGP-IRES-h $\left.\beta_{2}\right)$, respectively, as transfection markers, as previously described (Thompson et al., 2011).

Whole-cell voltage-clamp experiments of heterologous cells were performed as previously described (Thompson et al., 2011, 2012). Whole-cell voltage-clamp recordings were made at room temperature using an Axopatch 200B amplifier (Molecular Devices, LLC, Sunnyvale, CA, USA). Patch pipettes were pulled from borosilicate glass capillaries (Harvard Apparatus Ltd., Edenbridge, Kent, UK) with a multistage P-1000 Flaming-Brown micropipette puller (Sutter Instruments Co., San Rafael, CA, USA) and fire-polished using a microforge (Narashige MF-830; Tokyo, JP) to a resistance of 1.5-2.5 M $\Omega$. The pipette solution consisted of (in $\mathrm{mM}$ ): $10 \mathrm{NaF}, 105 \mathrm{CsF}, 20 \mathrm{CsCl}, 2$ EGTA, and 10 HEPES with pH adjusted to 7.35 with $\mathrm{CsOH}$ and osmolality adjusted to $300 \mathrm{mOsmol} / \mathrm{kg}$ with sucrose. The recording solution was continuously perfused with bath solution containing (in $\mathrm{mM}$ ): $145 \mathrm{NaCl}, 4 \mathrm{KCl}, 1.8 \mathrm{CaCl}_{2}, 1$ $\mathrm{MgCl}_{2}, 10$ glucose and 10 HEPES with $\mathrm{pH}$ adjusted to 7.35 with $\mathrm{NaOH}$ and osmolality 310 mOsmol/kg. For sodium-free recordings, the bath solution contained (in mM): 120 NMDG, 4 
$\mathrm{KCl}, 10 \mathrm{CaCl}_{2}, 2 \mathrm{MgCl}_{2}, 10$ glucose, and 10 HEPES with $\mathrm{pH}$ adjusted to 7.35 with $\mathrm{HCl}$ and osmolality $310 \mathrm{mOsmol} / \mathrm{kg}$.

Mice. Scn $2 a^{K 1422 E}$ mice on the C57BL/6J strain were generated using CRISPR/Cas9 to introduce the modification of K1422 by homology directed repair. A single nucleotide change was introduced in codon 1422 (AAA > GAA), resulting in a glutamate residue being encoded at the modified position. A single guide RNA (TCCTTTAAATGTGGCCTGTA) with low predicted off-target effects, and a $151 \mathrm{bp}$ repair oligo (5' -

CCTTGTTTCCACTTTTACTCTGATAATCTATTTCCTAAACTATAAAAAAGAGAAGAA GTATATATGTTGATTGTTTTACAGGCCACATTTE्GAAGGATGGATGGATATCATGTAT GCAGCTGTTGACTCAAGAAATGTAAGTTTACTTTGG) were delivered to C57BL/6J embryos at the two-cell stage using electroporation by the Northwestern University Transgenic and Targeted Mutagenesis Laboratory.

Potential founders were screened by PCR of genomic DNA using primers outside the repair oligo homology region (Table 1), and the region of interest was cloned into pCR-TOPO (ThermoFisher) and Sanger sequenced. The mosaic K1422E founder was backcrossed to C57BL/6J mice (Jackson Labs, \#000664, Bar Harbor, ME) to generate N1 offspring. N1 offspring were genotyped by Sanger sequencing to confirm transmission of the K1422E editing event and were screened for off-target events by Sanger sequencing of all potential sites with $<3$ mismatches. N1 males with the confirmed on-target event and without predicted off-target events were bred with C57BL/6J females to establish the line Scn2a $a^{\text {em1Kea }}$ (MGI:6390565), which is maintained as an isogenic strain on C57BL/6J by continual backcrossing of Scn $2 a^{K 1422 E /+}$ heterozygous mice (abbreviated $\operatorname{Scn} 2 a^{E /+}$ ) with inbred C57BL/6J mice. Heterozygous $\operatorname{Scn} 2 a^{E /+}$ 
and $\operatorname{Scn} 2 a^{+/+}$(wild-type, abbreviated WT) mice for experiments were obtained from this breeding at generations $>\mathrm{N} 3$.

Mice were maintained in a Specific Pathogen Free (SPF) barrier facility with a 14-h light/10-h dark cycle and access to food and water ad libitum. Both female and male mice were used for all experiments. All animal care and experimental procedures were approved by the Northwestern University and UC San Francisco Animal Care and Use Committees in accordance with the National Institutes of Health Guide for the Care and Use of Laboratory Animals. Principles outlined in the ARRIVE (Animal Research: Reporting of in vivo Experiments) guideline and Basel declaration (including the 3R concept) were considered when planning experiments.

Genotyping. DNA was isolated from tail biopsies using the Gentra Puregene Mouse Tail Kit according to the manufacturer's instructions (Qiagen, Valenica, CA, USA). Genomic DNA was digested with BamHI-HF (New England Biolabs, Ipswich, MA, USA) at $37^{\circ} \mathrm{C}$ for 1 hour, diluted 1:1 with nuclease-free water and used as template for digital droplet PCR (ddPCR) using ddPCR Supermix for Probes (No dUTP) (Bio-Rad, Hercules, CA, USA) and a custom TaqMan SNP Genotyping Assay (Life Technologies, Carlsbad, CA, USA) (Table 1). Reactions were partitioned into droplets using a QX200 droplet generator (Bio-Rad). PCR conditions were $95^{\circ} \mathrm{C}$ for $10 \mathrm{~min}$, then 44 cycles of $95^{\circ} \mathrm{C}$ for $30 \mathrm{~s}$ and $60^{\circ} \mathrm{C}$ for $1 \mathrm{~min}\left(\operatorname{ramp}\right.$ rate of $2^{\circ} \mathrm{C} / \mathrm{s}$ ) and a final inactivation step of $98{ }^{\circ} \mathrm{C}$ for $5 \mathrm{~min}$. Following amplification, droplets were analyzed on a QX200 droplet reader with Quantasoft v1.6.6 software (Bio-Rad).

Transcript analysis. Whole brain total RNA was extracted from WT and $S c n 2 a^{E /+}$ mice at 4 weeks of age using TRIzol reagent according to the manufacturer's instructions (Invitrogen, Carlsbad, CA, USA). First-strand cDNA was synthesized from $2 \mu \mathrm{g}$ of total RNA using 
oligo(dT) primer and Superscript IV reverse transcriptase (RT) according to the manufacturer's instructions (Life Technologies). First-strand cDNA samples were diluted 1:3 and $5 \mu \mathrm{L}$ was used as template. Quantitative ddPCR was performed using ddPCR Supermix for Probes (No dUTP) (Bio-Rad) and TaqMan Gene Expression Assays (Life Technologies) for mouse Scn2a (FAMMGB-Mm01270359_m1) and Tbp (VIC-MGB-Mm00446971_m1) as a normalization standard. Reactions were partitioned into droplets using a QX200 droplet generator (Bio-Rad).

Thermocycling conditions and analysis were performed as described for genotyping. Both assays lacked detectable signal in no-RT controls. Relative transcript levels were expressed as a ratio of $S c n 2 a$ concentration to $T b p$ concentration (normalized to the mean ratio for WT mice), with 8 biological replicates per genotype, balanced by sex. Statistical comparison between groups was made using Student's t-test (GraphPad Prism, San Diego, CA, USA).

Immunoblotting. Whole brain membrane proteins were isolated from WT and $\operatorname{Scn} 2 a^{E /+}$ mice at 4 weeks of age. Membrane fractions (50 $\mu \mathrm{g} / \mathrm{lane})$ were separated on a 7.5\% SDS-PAGE gel and transferred to nitrocellulose. Blots were probed with anti-Nav2.1 pAb (Alomone Labs, Jerusalem, ISR; \#ASC-002, RRID: AB_2040005; 1:200 dilution) and anti-mortalin/GRP75 mAb (Antibodies Inc, Davis, CA, USA; Neuromab N52A/42, RRID: 2120479; 1:1000 dilution), which served as a normalization standard. Alexa Fluor 790 goat anti-rabbit antibody (Jackson ImmunoResearch, West Grove, PA, USA; \#111-655-144, RRID: AB_2338086; 1:10,000 dilution) and 680 goat anti-mouse antibody (Jackson ImmunoResearch; \#115-625-146; RRID: AB_2338935; 1:10,000 dilution) were used to detect signal on an Odyssey imaging system (LiCOR, Lincoln, Nebraska USA). Relative protein levels were determined by densitometry with Image Studio (Li-COR) and expressed as a ratio of Nav1.2 to GRP75 (normalized to the mean 
ratio for WT mice), with 8 biological replicates per genotype, balanced by sex. Statistical comparison between groups was made using Student's t-test (GraphPad Prism).

Acutely dissociated neuron electrophysiology. Hippocampal pyramidal neurons from P21-P24

WT or $\operatorname{Scn} 2 a^{E /+}$ were isolated as previously described (Mistry et al., 2014; Thompson et al., 2017). Whole-cell voltage-clamp recordings were made at room temperature using an Axopatch 200B amplifier (Molecular Devices) in the absence and presence of $500 \mathrm{nM}$ tetrodotoxin (TTX). Patch pipettes were pulled from borosilicate glass capillaries (Harvard Apparatus Ltd., Edenbridge, Kent, UK) with a multistage P-97 Flaming-Brown micropipette puller (Sutter Instruments) and fire-polished using a microforge (Narashige MF-830) to a pipette resistance of 1.5-2.5 M $\Omega$. The pipette solution consisted of (in $\mathrm{mM}$ ) $5 \mathrm{NaF}, 105 \mathrm{CsF}, 20 \mathrm{CsCl}, 2 \mathrm{EGTA}$, and 10 HEPES with $\mathrm{pH}$ adjusted to 7.35 with $\mathrm{CsOH}$ and osmolarity adjusted to $280 \mathrm{mOsmol} / \mathrm{kg}$ with sucrose. The recording chamber was continuously perfused with a bath solution containing in (mM) $20 \mathrm{NaCl}, 100 \mathrm{~N}$-methyl-D-glucamine, $10 \mathrm{HEPES}, 1.8 \mathrm{CaCl}_{2} \cdot 2 \mathrm{H}_{2} \mathrm{O}, 2 \mathrm{MgCl}_{2} \cdot 6 \mathrm{H}_{2} \mathrm{O}$, and 20 tetraethylammonium chloride with $\mathrm{pH}$ adjusted to 7.35 with $\mathrm{HCl}$ and osmolarity adjusted to $310 \mathrm{mOsmol} / \mathrm{kg}$ with sucrose.

Voltage-clamp pulse generation and data collection were done using Clampex 10.4 (Molecular Devices). Whole-cell capacitance was determined by integrating capacitive transients generated by a voltage step from $-120 \mathrm{mV}$ to $-110 \mathrm{mV}$ filtered at $100 \mathrm{kHz}$ low pass Bessel filtering. Series resistance was compensated with prediction $>70 \%$ and correction $>90 \%$ to assure that the command potential was reached within microseconds with a voltage error $<3 \mathrm{mV}$. Leak currents were subtracted by using an online $\mathrm{P} / 4$ procedure. All whole-cell currents were filtered at $5 \mathrm{kHz}$ low pass Bessel filtering and digitized at $50 \mathrm{kHz}$. 
Modeling. Channel biophysical properties and models were generated as described in Spratt et al., 2010, with APs generated with a $2.1 \mathrm{nA}$ current applied at the soma. A K1422E model was generated by first assuming equal permeabilities for $\mathrm{Cs}^{+}$and $\mathrm{K}^{+}$, and a relative permeability for $\mathrm{Na}^{+}$vs $\mathrm{K}^{+}$of 1:0.7, as described in Heinemann et al., 1992.

Ex vivo whole-cell electrophysiology. Experiments were performed in accordance with guidelines set by the University of California Animal Care and Use Committee. $250 \mu \mathrm{m}$-thick coronal slices containing medial prefrontal cortex were obtained from $\operatorname{Scn} 2 a^{E /+}$ and WT littermate mice of both sexes aged P35-45. Cutting solution contained, in mM: $87 \mathrm{NaCl}, 25$ $\mathrm{NaHCO}_{3}, 25$ glucose, 75 sucrose, $2.5 \mathrm{KCl}, 1.25 \mathrm{NaH}_{2} \mathrm{PO}_{4}, 0.5 \mathrm{CaCl}_{2}$, and $7 \mathrm{MgCl}_{2}$, bubbled with $5 \% \mathrm{CO}_{2} / 95 \% \mathrm{O}_{2}$. After cutting, slices were incubated in the same solution for $30 \mathrm{~min}$ at $33^{\circ} \mathrm{C}$, then at room temperature until recording. Recording solution contained, in mM: $125 \mathrm{NaCl}, 2.5$ $\mathrm{KCl}, 2 \mathrm{CaCl}_{2}, 1 \mathrm{MgCl}_{2}, 25 \mathrm{NaHCO}_{3}, 1.25 \mathrm{NaH}_{2} \mathrm{PO}_{4}$, and 25 glucose, bubbled with $5 \% \mathrm{CO}_{2} / 95 \%$ $\mathrm{O}_{2}$, with an osmolarity of $\sim 310$ mOsm.

For whole-cell recording of layer 5b pyramidal cells, slices were visualized using Dodt contrast optics on a purpose built 2-photon microscope. Patch electrodes were pulled from Schott 8250 glass (3-4 M $\Omega$ tip resistance) and filled with a solution containing, in mM: $113 \mathrm{~K}-$ gluconate, 9 HEPES, $4.5 \mathrm{MgCl}_{2}$, 14 Tris2-phosphocreatine, 4 Na2-ATP, 0.3 Tris-GTP, $600 \mu \mathrm{M}$ OGB-5N, 0.1 $\mu \mathrm{M}$ EGTA and $20 \mu \mathrm{M}$ AlexaFluor 594; 290 mOsm, pH 7.2-7.25.

Electrophysiological data were acquired using a Multiclamp 700B amplifier (Molecular Devices) and custom routines in IgorPro (Wavemetrics, Portland, OR, USA). Data were acquired at 50 $\mathrm{kHz}$ and Bessel filtered at $20 \mathrm{kHz}$. Recordings were made using quartz electrode holders to minimize electrode drift within the slice, enabling stable imaging of diffraction-limited spots in close proximity to the recording electrode (Sutter Instruments). Recordings were excluded if 
series resistance exceeded $14 \mathrm{M} \Omega$ or if the series resistance changed by greater than $20 \%$ over the course of the experiment. Fast pipette capacitance, as measured in cell-attached voltage clamp mode (typically 10-12 pF), was compensated 50\% in current-clamp recordings, and data were corrected for a $12 \mathrm{mV}$ junction potential.

Two-Photon Imaging. Imaging was performed as described previously (Lipkin et al., 2021). A Coherent Ultra II laser was tuned to $810 \mathrm{~nm}$ and epifluorescence and transfluorescence were collected through a $60 \mathrm{x}, 1.0 \mathrm{NA}$ objective and a 1.4 NA oil immersion condenser, respectively (Olympus). Dichroic mirrors and band-pass filters (575 DCXR, ET525/70 m-2p, ET620/60 m2p, Chroma) were used to split fluorescence into red and green channels. HA10770-40 photomultiplier tubes (PMTs, Hamamatsu) selected for $>50 \%$ quantum efficiency and low dark counts captured green fluorescence (Oregon Green BAPTA 5N). Red fluorescence (AlexaFluor 594) was captured using R9110 PMTs (Hamamatsu).

Fluorescence data were collected in a pointscan configuration, where the laser was parked at single diffraction-limited spots along the AIS membrane. Data were collected over a series of 5 points spanning $2 \mu \mathrm{m}$ (e.g., separated by $0.5 \mu \mathrm{m}$ ), in regions either $3-5 \mu \mathrm{m}$ from the axon hillock (proximal AIS) or 28-30 $\mu \mathrm{m}$ from the axon hillock (distal AIS). Each point was imaged at $20 \mathrm{kHz}$ for $25 \mathrm{~ms}$ preceding and $100 \mathrm{~ms}$ following an AP. Individual points were imaged in a sequence of $2,4,1,3,5$, with 2 being the point most proximal to the soma. Individual APs within the set of 5 points were separated by $250 \mathrm{~ms}$. Data were averaged over 40 repetitions for each site and subsequently averaged over all 5 spots for a total averaging of 200 sampled APs. Data were then smoothed using a 40-point binomial filter in IgorPro for analysis. Calcium transients were normalized to saturating conditions $\left(\Delta \mathrm{G} / \mathrm{G}_{\text {sat }}\right)$ as previously described (Lipkin et 
al., 2021). Transient onset was defined as the time at which signals exceeded root-mean-squared noise levels of the $20 \mathrm{~ms}$ period preceding AP onset.

Video-EEG monitoring. Male and female WT and Scn $2 a^{E /+}$ mice were implanted with prefabricated 3-channel EEG headmounts (Pinnacle Technology, Lawrence, KS, USA) at 4-6 weeks of age. Briefly, mice were anesthetized with ketamine/xylazine and place in a stereotaxic frame. Headmounts with four stainless steel screws that serve as cortical surface electrodes were affixed to the skull with glass ionomer cement. Anterior screw electrodes were $0.5-1 \mathrm{~mm}$ anterior to bregma and $1 \mathrm{~mm}$ lateral from the midline. Posterior screws were $4.5-5 \mathrm{~mm}$ posterior to bregma and $1 \mathrm{~mm}$ lateral from the midline. EEG1 represents recordings the right posterior to left posterior (interelectrode distance $\approx 2 \mathrm{~mm}$ ). EEG2 represents recordings form right anterior to left posterior (interelectrode distance $\approx 5 \mathrm{~mm}$ ). The left anterior screw served as the ground connection. Following at least $48 \mathrm{~h}$ of recovery, tethered EEG and video data were continuously collected from freely moving mice with Sirenia acquisition software (Pinnacle Technology) using a sampling rate of $400 \mathrm{~Hz}$ as previously described (Hawkins et al., 2016). At least $96 \mathrm{~h}$ of EEG data were acquired from each subject (WT range: 96-672 h/mouse $(\mathrm{n}=17$ mice; 5-11 weeks of age); $\operatorname{Scn} 2 a^{E /+}$ range: $168-672 \mathrm{~h} /$ mouse $(\mathrm{n}=15$ mice; $5-13$ weeks of age)). Raw data was notch filtered with a $1 \mathrm{~Hz}$ window around 60 and $120 \mathrm{~Hz}$ prior to analysis. Video-EEG records were manually reviewed with Sirenia software, MATLAB (MathWorks, Natick, MA, USA) and EEGLAB (Swartz Center for Computational Neuroscience, CA, USA) by 2 independent reviewers blinded to genotype. Spontaneous seizures were defined as isolated events with an amplitude of $\geq 3$ times baseline, duration of $\geq 10 \mathrm{~s}$, and that show evolution in power and amplitude. Epileptiform discharges were defined as isolated events with a spike and overriding fast activity, an amplitude of $\geq 3$ times baseline, duration of $150-500 \mathrm{~ms}$, and with increased 
power in frequencies $>20 \mathrm{~Hz}$ compared to baseline. Samples with high baseline artifact were excluded from analysis.

Flurothyl seizure induction. Susceptibility to seizures induced by the chemoconvulsant flurothyl (Bis(2,2,2-trifluoroethyl) ether, Sigma-Aldrich, St. Louis, MO, USA) was assessed in WT and $\operatorname{Scn} 2 a^{E /+}$ mice at 6-9 weeks of age. Flurothyl was introduced into a clear, plexiglass chamber (2.2 L) by a syringe pump at a rate of $20 \mu \mathrm{L} / \mathrm{min}$ and allowed to volatilize. Latencies to first myoclonic jerk, generalized tonic-clonic seizure (GTCS) with loss of posture, and time interval between these phases were recorded $(n=19-20$ per genotype and sex). Groups were compared using Student's t-test (GraphPad Prism), with sexes considered separately.

Neurobehavioral assays. Male and female WT and $S c n 2 a^{E /+}$ mice were tested between 6 and 11 weeks of age. Male and female mice were tested separately with at least a one-hour delay between sessions. For all experiments, mice were acclimated in the behavior suite with white noise for $1 \mathrm{~h}$ prior to behavioral testing. At the end of each procedure, mice were placed into a clean cage with their original littermates. Behavioral testing was performed by experimenters blinded to genotype. For the initial cohort of mice, evaluation occurred over 6 weeks, with one assay performed each week: week 1- zero maze; week 2- light-dark exploration; week 3- open field; week 4- rotarod; week 5- three-chamber social interaction; and week 6- olfactory habituation/dishabituation test. The remaining assays were performed on a new cohort of mice, with one assay performed each week: week 1- marble burying; week 2- Y-Maze (not reported); and week 3- buried food. For all measures, males and females were considered separately. Statistical comparison between groups were made using Student's t-test or two-way repeated measures ANOVA with Sidak's post-hoc comparisons, unless otherwise indicated (Table 2). 
Zero maze. Mice were evaluated for anxiety-related behavior in an elevated zero maze at 6 weeks of age. The maze consists of an annular platform (diameter- $46 \mathrm{~cm}$; elevation- $50 \mathrm{~cm}$ ) that is divided into equally sized quadrants, alternating between open and enclosed (wall height- 17 $\mathrm{cm})$. This configuration lacks the ambiguous center region associated with the elevated plus maze (Shepherd et al., 1994). Individual mice were placed near an enclosed arm of the maze and allowed to freely explore for $5 \mathrm{~min}$. Limelight software (Actimetrics, Wilmette, IL, USA) was used to video record each trial. Ethovison XT software (Noldus, Leesberg, VA, USA) was used to track the position of the mouse, and calculate distance traveled, mean velocity, and time spent in closed or open arms $(n=12-14$ per genotype and sex $)$. Trials where mice fell off the maze were excluded from analysis.

Light-dark exploration. Mice were evaluated for anxiety-related behavior in a light-dark box at 7 weeks of age. The plexiglass box is divided into equally sized light (400 lx) and dark (0 lx) sections $(20 \times 40 \mathrm{~cm})$ separated by a central partition plate with a small opening $(3 \mathrm{x} 5 \mathrm{~cm})$ to allow transit between sections. Individual mice were placed in the center of the light section, facing away from the dark section, and allowed to freely explore for $10 \mathrm{~min}$. Limelight software was used to video record each trial. Ethovison XT software was used to track the position of the mouse, and calculate time spent in light or dark sections $(n=13-15$ per genotype and sex $)$.

Open field. Mice were evaluated for baseline activity and anxiety-related behavior in an open field at 8 weeks of age. Individual mice were placed in the center of an open field arena (46 x 46 $\mathrm{cm}$ ) and allowed to freely explore for $30 \mathrm{~min}$. Limelight software was used to video record each trial. Ethovison XT software was used to track the position of the mouse, and calculate total distance traveled, mean velocity, and time spent in the periphery ( $9 \mathrm{~cm}$ from wall) and center $(28$ $\mathrm{x} 28 \mathrm{~cm})(\mathrm{n}=13-15$ per genotype and sex $)$. 
Rotarod. Mice were evaluated for motor coordination and balance using an accelerating rotarod (Panlab, Harvard Apparatus, Barcelona, Spain) at 9 weeks of age. Up to 5 mice were placed on the rotating rod that accelerated from 4 to 40 RPM over 5 min. Mice were given three trials per day for 3 consecutive days with an inter-trial interval of $15 \mathrm{~min}$. Latency to fall from the rotating rod was automatically recorded $(n=11-14$ per genotype and sex).

Three-chamber social interaction. Mice were evaluated for sociability and preference for social novelty using a three-chamber social interaction test at 10 weeks of age. The three-chamber apparatus consists of a plexiglass box divided into equally sized chambers $(21 \mathrm{x} 42 \mathrm{~cm})$ separated by transparent plates with small openings $(3 \times 5 \mathrm{~cm})$ to allow transit between chambers. All chambers were subject to uniform illumination (170 1x). One wire cylinder-shaped cage was placed in the center of each side chamber and used to enclose a sex-matched, 8-12week-old C57BL/6J stranger mouse during the testing phase of the assay. During an initial habituation phase, individual test mice were placed in the middle of the center chamber and allowed to freely explore for $10 \mathrm{~min}$. During the first test phase (sociability), a stranger mouse was randomly placed in a wire cage in one of the side chambers and the test mouse was allowed to freely explore for $10 \mathrm{~min}$. During the second testing phase (social novelty), the stranger mouse from the sociability phase remained in place and was then considered familiar. Then, a second stranger mouse was placed in the wire cage in the opposite side chamber and the test mouse was allowed to freely explore for $10 \mathrm{~min}$. Limelight software was used to video record each trial. Ethovison XT software was used to track the position of the test mouse, and calculate time spent in each chamber and time spent sniffing stranger mice or empty wire cage $(n=11-14$ per genotype and sex). Trials where mice spent $>10 \%$ of trial time on top of the wire cages were excluded. 
Olfactory habituation/dishabituation test. Olfactory impairment could interfere with social behaviors, therefore olfactory discrimination for social and non-social odor was evaluated in 11 week old mice as previously described (Yang and Crawley, 2010). Dry applicators were used to present odor stimuli to test mice: non-social odors- distilled water, almond extract (McCormick, Hunt Valley, MD, USA; 1:100 dilution), and banana extract (McCormick; 1:100 dilution); social odors- unfamiliar social cage (same sex), unfamiliar social cage (opposite sex). During an initial habituation phase, individual mice were placed in a clean testing cage with a clean dry applicator and allowed to freely explore for $30 \mathrm{~min}$. During the testing phase, odor stimuli were presented to test mice for three consecutive trials each (15 trials total) in the following order: (1) distilled water, (2) almond extract, (3) banana extract, (4) same sex cage, (5) opposite sex cage. Each odor was presented for $2 \mathrm{~min}$ with an inter-trial interval of $1 \mathrm{~min}$. Trials were video recorded and sniffing time was evaluated manually by an independent reviewer blinded to genotype ( $\mathrm{n}=13-14$ per genotype and sex).

Marble burying task. Marble burying was evaluated in 6-week-old mice to assess phenotypes related to anxiety- and obsessive-compulsive behavior. Individual mice were placed in a clean testing cage with $4 \mathrm{~cm}$ of bedding and acclimated for $15 \mathrm{~min}$. Mice were then briefly removed from the cage while bedding was flattened and 20 marbles were evenly placed across the cage in a 5 x 4 matrix with a small open space at the front of the cage. A baseline image of the cage was taken prior to reintroduction of the mouse and reimaged after the 30-min trial. The two images were compared for the number of marbles buried, defined by at least $50 \%$ of the marble being submerged under the bedding $(n=13-14$ per genotype and sex $)$.

Buried food test. Mice were evaluated for olfactory-guided behavior using a buried food task at 8 weeks of age as previously described (Yang and Crawley, 2010). Teddy Grahams (Nabisco, 
Hanover, NJ, USA) have been established as a palatable food stimulus in this assay. In order to familiarize test mice with the stimulus odor, one cookie was placed in the home cage of all subjects for 3-4 consecutive days prior to testing. In order to drive olfactory-guided behavior, mice were transferred to a clean cage with their original littermates without access to food 15-18 $\mathrm{h}$ before testing. On the testing day, single cookies were buried in a random corner of clean cages with $3 \mathrm{~cm}$ of bedding. Individual mice were placed in a clean testing cage and latency to find the food stimulus was recorded ( $\mathrm{n}=13-14$ per genotype and sex). Mice that failed to find the food stimulus after 15 min received a latency score of $900 \mathrm{~s}$.

Statistical Analysis. Table 2 summarizes statistical tests used for all comparisons along with computed values. D’Agostino \& Pearson tests for normality were used to determine parametric versus non-parametric test selection. F test to compare variances was used to determine where to apply correction for unequal standard deviations.

\section{Results}

\section{K1422E alters channel ion permeability in heterologous expression systems.}

Previous biophysical characterizations of rat Nav1.2 channels expressed in Xenopus oocytes suggested that K1422E alters channel ion selectivity, increasing permeation for potassium and calcium (Heinemann et al., 1992; Schlief et al., 1996). Thus, before assessing K1422E function in mice, we first assessed channel function in HEK293T cells. Current density was significantly lower in cells expressing K1422E compared to WT channels (Current density at -10 mV: WT: $427.6 \pm 95.7 \mathrm{pA} / \mathrm{pF}, \mathrm{n}=7, \mathrm{~K} 1422 \mathrm{E}:-72.0 \pm 18.7 \mathrm{pA} / \mathrm{pF}, \mathrm{n}=7, \mathrm{p}=0.0033)$ (Figure 1B-C).

Furthermore, the reversal potential was more hyperpolarized (WT: $66.4 \pm 1.1 \mathrm{mV}, \mathrm{n}=7, \mathrm{~K} 1422 \mathrm{E}$ : $34.4 \pm 1.2 \mathrm{mV}, \mathrm{n}=7, \mathrm{p}<0.0001$; Figure 1D), suggestive of enhanced potassium permeability. To 
test whether K1422E channels were also permeable to calcium, recordings were made in sodiumfree solutions with a higher calcium concentration $(10 \mathrm{mM})$. Consistent with previous studies of bacterial and vertebrate Nav1 channels (Favre et al., 1996; Naylor et al., 2016), the WT channel showed no inward calcium-mediated current under these conditions (WT: $4.3 \pm 0.5 \mathrm{pA} / \mathrm{pF}, \mathrm{n}=7$ ). By contrast, K1422E channels supported appreciable inward current (WT: $-44.4 \pm 16.2$ pA/pF, $\mathrm{n}=7, \mathrm{p}=0.0109$ ), indicating that the variant promoted calcium permeable (Figure 1B, E).

Based on previous biophysical characterizations of K1422E and our own performed here (Heinemann et al., 1992; Schlief et al., 1996), we developed a channel model and compartmental neuronal model to provide testable predictions for how K1422E affects neuronal function (Figure 2). The K1422E variant was modeled first by introducing potassium permeability to an established Nav1.2 channel model at a ratio of 1:0.7 (Na:K), and assuming that $\mathrm{Cs}^{+}$and $\mathrm{K}^{+}$permeability were comparable, as determined previously (Heinemann et al., 1992). Subsequently, calcium permeability was increased to levels that best captured the reversal potential observed in HEK293T cells, with reversals for $\mathrm{Na}^{+}, \mathrm{Cs}^{+}\left(\approx \mathrm{K}^{+}\right)$, and $\mathrm{Ca}^{2+}$ determined from the Goldman-Hodgkin-Katz equation (Figure 1C). This was best described by relative permeabilities for $\mathrm{Na}^{+}, \mathrm{K}^{+}$and $\mathrm{Ca}^{2+}$ of 1:0.7:0.8. Resultant current density relative to WT was reduced modestly in the model, but less markedly as observed in experiments (Figure 2A, B; Heinemann et al., 1992). This is because calcium has been shown to antagonize K1422E channels, reducing overall current density (Heinemann et al., 1992). We therefore developed an additional channel model with reduced current density to match empirical observations, which was mimicked by reducing the number of K1422E channels relative to WT. This K1422E channel model was incorporated into previously established models of cortical pyramidal cells (Ben-Shalom et al., 2017) at a 50:50 ratio with a wild-type Nav1.2 allele, and at reduced relative density to mimic increased calcium antagonism. 
APs generated by somatic current injection had features consistent with partial LoF conditions, with reductions in peak AP speed that approached, but did not match those observed in $S c n 2 a^{+/-}$ model neurons (Figure 2C-D; 6.4, 16.2, and 26.8\% for reduction in AP speed for K1422E without calcium antagonism, with calcium antagonism, and $\operatorname{Scn} 2 a^{+/-}$conditions, respectively).

Generation and initial characterization of Scn $2 a^{K 1422 E}$ Mice. We developed an in vivo model of the NDD-associated $S C N 2 A$ p.K1422E pathogenic variant by using CRISPR/Cas9 genome editing to introduce the K1422E single nucleotide variant into mouse Scn2a via homology directed repair (Figure 3A). $S c n 2 a^{K 1422 E /+}$ heterozygous mutants (abbreviated as $S c n 2 a^{E /+}$ ) were born at the expected Mendelian ratios and there was no difference in body weight compared to WT littermates when measured at 4 weeks (WT: $13.5 \pm 0.36 \mathrm{~g}, \mathrm{n}=13, \operatorname{Scn} 2 a^{E /+}: 13.6 \pm 0.49 \mathrm{~g}$, $\mathrm{n}=14, \mathrm{p}=0.8349$, Student's t-test). We used droplet digital RT-PCR (RT-ddPCR) and immunoblotting to evaluate whole brain expression of $S c n 2 a$ transcript and Nav1.2 protein, respectively, and observed no difference in expression between $\operatorname{Scn} 2 a^{E /+}$ and WT mice (Figure 3B-D). Similar to constitutive knockout of $S c n 2 a$, mice homozygous for K1422E $\left(\operatorname{Scn} 2 a^{E / E}\right)$ exhibit $100 \%$ mortality by postnatal day 1 (Planells-Cases et al., 2000). Because SCN2Aassociated NDD is associated with heterozygous variants, our experiments focused on comparing $\operatorname{Scn} 2 a^{E /+}$ mice to WT littermate controls.

\section{Scn $2 a^{K 1422 E}$ channels affect pyramidal cell excitability in allocortex and neocortex. Nav1.2}

channels are expressed in excitatory pyramidal cells throughout hippocampus and neocortex $(\mathrm{Hu}$ et al., 2009; Lorincz and Nusser, 2010). To determine whether K1422E channels are functionally expressed in $\operatorname{Scn} 2 a^{E /+}$ mice, we performed a series of experiments in dissociated neuronal culture 
and ex vivo using acute slices. First, we acutely isolated hippocampal neurons from P24-25 WT and $\operatorname{Scn} 2 a^{E /+}$ mice and assessed sodium currents derived from perisomatic channels maintained in the cells. This includes somatic sodium channels, which are predominantly Nav1.6 isoforms in hippocampal neurons (Lorincz and Nusser, 2010; Spratt et al., 2019), but also a fraction of the proximal axon initial segment, which is enriched with Nav1.2 channels (Lorincz and Nusser, 2010). Consistent with current arising largely from Nav1.6 isoforms, dissociated cell sodium current were not altered appreciably in $\operatorname{Scn} 2 a^{E /+}$ conditions; however, the reversal potential of this sodium current was hyperpolarized $\sim 6 \mathrm{mV}$ in $\operatorname{Scn} 2 a^{E /+}$ cells (WT: $38.5 \pm 2.2 \mathrm{mV} \mathrm{n}=11$, $\operatorname{Scn} 2 a^{E /+}: 32.7 \pm 1.0 \mathrm{mV}, \mathrm{n}=9, \mathrm{p}=0.0364$; Figure 4A, D). This suggests that K1422E channels may be contributing to this current, albeit at levels that cannot be resolved within cell-to-cell variability in total current amplitude. To further resolve K1422E channels in such preparations, we reassessed currents in $500 \mathrm{nM}$ TTX, as the K1422E mutation has been shown to reduce TTX sensitivity (Terlau et al., 1991). In these conditions, Scn $2 a^{E /+}$ neurons produced an appreciable TTX-resistant current that reversed at more hyperpolarized potentials (WT: $35.6 \pm 3.9 \mathrm{mV} \mathrm{n}=8$, $\operatorname{Scn} 2 a^{E /+}: 16.5 \pm 2.7 \mathrm{mV}, \mathrm{n}=9, \mathrm{p}=0.0006$; Figure 4B, D). Importantly, the remaining TTXsensitive currents, which is not contaminated by currents mediated by K1422E-containing channels, were comparable to WT in current density and reversal potential (WT: $43.9 \pm 1.7 \mathrm{mV}$ $\mathrm{n}=10, \operatorname{Scn} 2 a^{E /+}: 46.8 \pm 2.9 \mathrm{mV}, \mathrm{n}=9, \mathrm{p}=0.0364 ;$ Figure 4C-D).

Nav1.2 channels contribute to a larger fraction of somatic sodium influx in neocortical pyramidal cells. In these cells, progressive loss of Scn2a alleles, either from constitutive heterozygous knockout, or conditional homozygous knockout, leads to progressive decrements in the speed of the somatic component of an AP (Spratt et al., 2019, 2021). Based on the reduced current density observed for K1422E above, we hypothesized that the AP waveform would be 
similarly affected by this variant. To test this, we made whole-cell current-clamp recordings from layer $5 \mathrm{~b}$ pyramidal cells in acute slices containing medial prefrontal cortex of Scn $2 a^{E /+}$ mice aged P37-45. Scn $2 a^{E /+}$ pyramidal cells had slower peak AP speed (WT: $605 \pm 18 \mathrm{~V} / \mathrm{s}, \mathrm{n}=$ 14; $\mathrm{E} /+: 527 \pm 21 \mathrm{~V} / \mathrm{s}, \mathrm{n}=13 ; \mathrm{p}=0.01$, unpaired $\mathrm{t}$-test), but were otherwise indistinguishable from cells assayed from littermate controls (Figure 5). This reduction in AP speed (13\%) is smaller than that observed in $\operatorname{Scn} 2 a^{+/-}$heterozygotes (27\%; Spratt et al. 2021), consistent with a reduction, but not elimination, of current density through channels with the K1422E variant. Furthermore, changes in AP speed were best fit by compartmental model predictions that combined changes in channel permeabilities with a reduction in current density due to calcium antagonism (predicted 16\% reduction) (Figure 2).

These changes in AP waveform suggest that K1422E-Nav1.2 channels are functional in neocortical pyramidal cells. To test whether calcium influx through Nav1.2 channels can be observed in intact neurons, we imaged AP-evoked calcium transients in the AIS with high spatiotemporal precision using 2-photon pointscan imaging. Under normal conditions, calcium influx occurs during AP repolarization in all regions of the axon, including the AIS, and can be separated temporally from sodium influx occurring during AP depolarization (Geiger and Jonas 2000; Ritzau-Jost et al. 2014; Rowan, Tranquil, and Christie 2014; Filipis and Canepari 2021; Lipkin et al. 2021; but see Hanemaaijer et al. 2020). But in cells expressing K1422E channels, calcium influx may also occur during AP depolarization in regions enriched with Nav1.2 channels. In mature pyramidal neurons, Nav1.2 channels are clustered densely in a region of the AIS proximal to the soma, whereas Nav1.6 channels are enriched in the distal AIS (Figure 6A; $\mathrm{Hu}$ et al., 2009). Therefore, we imaged the proximal and distal initial segment, $5 \mu \mathrm{m}$ and $30 \mu \mathrm{m}$ from the axon hillock, respectively, corresponding to regions enriched or lacking Nav1.2 
channels (Figure 6B). Consistent with a lack of Nav1.2 channels in the distal AIS, there were no differences in the amplitude or timing of AP-evoked calcium transients in the distal AIS. By contrast, calcium transients were larger and occurred earlier, before AP membrane potential peaked, in the proximal AIS of $S c n 2 a^{E /+}$ cells (Amplitude, WT: $2.8 \pm 0.2 \Delta \mathrm{G} / \mathrm{G}$ sat, E/+: $3.8 \pm 0.3$ $\Delta \mathrm{G} / \mathrm{G}_{\mathrm{sat}} \mathrm{p}=0.014$; timing relative to AP peak, WT: $0.62 \pm 0.15 \mathrm{~ms}, \mathrm{n}=12, \mathrm{E} /+:-0.17 \pm 0.13 \mathrm{~ms}$, $\mathrm{n}=10 ; \mathrm{p}<0.001$, unpaired t-test; Figure 6B-D). Thus, these data indicate that Nav1.2-K1422E channels flux calcium into the cell, and that this influx occurs during AP depolarization in the AIS.

Scn $2 a^{K 1422 E}$ mice exhibit abnormalities in EEG and alterations in seizure threshold. The child with the SCN2A p.K1422E variant initially presented with treatment-refractory infantile spasms at 13 months of age and went on to develop other seizure types (Sundaram et al., 2013). As previously discussed, seizure phenotypes have been associated with GoF and LoF effects on SCN2A, in both humans and mice (Ogiwara et al., 2009, 2018; Gazina et al., 2010; Sanders et al., 2018). The above data suggest that K1422E has mixed effects on channel function: namely, LoFlike effects with respect to neuronal excitability, as well as aberrant ion influx. How this mixed channel phenotype might affect brain activity and contribute to seizure susceptibility is unknown. Therefore, to evaluate $S c n 2 a^{E /+}$ mice for spontaneous seizures and epileptiform events, juvenile (4-6 weeks) mice were implanted with EEG headmounts for video-EEG monitoring which occurred from 5-11 weeks of age. $\operatorname{Scn} 2 a^{E /+}$ mice exhibited spontaneous localized seizures that occurred during sleep without any observable behavioral changes (Figure 7A-B). These seizures occurred rarely $\left(<1\right.$ per week) and were not observed in all $\operatorname{Scn} 2 a^{E /+}$ mice. Similar events were never observed in WT mice. $\operatorname{Scn} 2 a^{E /+}$ mice also exhibited interictal epileptiform 
discharges, including isolated high amplitude spikes with overriding fast activity that had higher power across low and high frequencies up to $170 \mathrm{~Hz}$ (Figure 7C-D). These events occurred at a rate of 2-5 events per 8 hours when quantified across a window that included 4-hour epochs from the light and dark phases.

Since these spontaneous seizures in $\operatorname{Scn} 2 a^{E /+}$ mice appear to be rare and difficult to observe due to a lack of an obvious behavioral component, we next asked how the $\operatorname{Scn} 2 a^{K 1422 E}$ variant affects seizure susceptibility in an induced-seizure paradigm. We used the volatile chemoconvulsant flurothyl, a GABAA antagonist (Ferland, 2017), to induce a stereotyped progression to generalized tonic-clonic seizures (GTCS) in juvenile (6-9 weeks of age) Scn $2 a^{E /+}$ and WT mice. While latency to first myoclonic jerk was not affected by genotype, latency to first GTCS (defined as characteristic limb flexion/extension with loss of posture) was affected by genotype (Table 2). Both male and female $\operatorname{Scn} 2 a^{E /+}$ mice had a higher threshold for flurothylinduced seizures compared to sex-matched WT littermates $(\mathrm{p}<0.0001$ for males; $\mathrm{p}=0.0282$ for females). Average latency was $247 \pm 13 \mathrm{sec}$ for $\operatorname{Scn} 2 a^{E /+}$ males, $175 \pm 8 \mathrm{sec}$ for WT males, 257 $\pm 21 \mathrm{sec}$ for $\operatorname{Scn} 2 a^{E /+}$ females, and $177 \pm 10 \mathrm{sec}$ for WT females (Figure 7E). We also noted that the data reflecting latency to first GTCS in $\operatorname{Scn} 2 a^{E /+}$ females was abnormally distributed compared to data from WT females. This effect was reproducible in three separate cohorts of $\operatorname{Scn} 2 a^{E /+}$ and WT females (Figure 7F). Time to progress from the first myoclonic jerk to the first GTCS was also affected by genotype (Table 2). Both males and female $\operatorname{Scn} 2 a^{E /+}$ mice progressed more slowly compared to sex-matched WT controls $(\mathrm{p}<0.0001$ for males and $\mathrm{p}=$ 0.035 for females). Average progression time was $120 \pm 13 \mathrm{sec}$ for $\operatorname{Scn} 2 a^{E /+}$ males versus $48 \pm 8$ sec for WT males, and $109 \pm 19 \sec$ for $\operatorname{Scn} 2 a^{E /+}$ females versus $52 \pm 10 \sec$ for WT females (Figure 7G). The above data suggest that rare spontaneous seizures occur in $\operatorname{Scn} 2 a^{E /+}$ mice, but 
they remain localized in parieto-occipital cortex. Furthermore, slower progression to flurothylinduced GTCS indicates resistance to seizure spreading in $\operatorname{Scn} 2 a^{E /+}$ mice, consistent with the localized nature of spontaneous seizures observed using EEG.

Lower anxiety-related behavior in Scn $2 a^{K 1422 E}$ mice. There is evidence to suggest that individuals with ASD are at increased risk for co-morbid anxiety (van Steensel et al., 2011; Perihan et al., 2021) and anxiety-related behavior is frequently assessed in mouse models of ASD-related genes, including Scn2a (Silverman et al., 2010; Léna and Mantegazza, 2019; Spratt et al., 2019; Tatsukawa et al., 2019). We used zero maze, light-dark exploration, and open field assays to assess anxiety-related behavior in $S c n 2 a^{E /+}$ and WT mice. These assays take advantage of mouse thigmotaxis and phototaxic aversion to define anxiety-related behavior. More time spent in exposed, well-lit areas compared to dark, enclosed areas indicates lower anxiety-related behavior. In the zero-maze assay, time spent in the open versus closed arms of the maze was significantly higher in both male and female $\operatorname{Scn} 2 a^{E /+}$ mice compared to sex-matched WT controls $\left(\mathrm{p}=0.0023\right.$ for males; $\mathrm{p}=0.0297$ for females, respectively). On average, $S c n 2 a^{E /+}$ males spent nearly twice as long $(30.5 \pm 4.1 \%)$ in the open arms compared to WT males $(15.3 \pm$ $2.2 \%$; Figure 8A). Scn $2 a^{E /+}$ females also spent more time in the open arms $(34.8 \pm 4.9 \%)$ compared to WT females $(22.0 \pm 2.0 \%$; Figure $8 \mathrm{~A})$. During the light-dark exploration assay, time spent in the exposed light zone versus the enclosed dark zone was significantly affected by genotype ( $\mathrm{p}=0.0367$ for both male and female comparisons). On average, $\operatorname{Scn} 2 a^{E /+}$ males spent more time $(29.2 \pm 3.2 \%)$ in the light zone compared to WT males $(20.9 \pm 2.0 \%$; Figure $8 \mathrm{~B})$. $\operatorname{Scn} 2 a^{E /+}$ females also spent more time in the light zone $(32.1 \pm 3.5 \%)$ compared to WT females $(21.1 \pm 1.7 \%$; Figure 8B). In the open field assay, time spent in the exposed center zone of the 
apparatus versus the periphery was significantly affected by genotype when comparing $\operatorname{Scn} 2 a^{E /+}$ and WT females $(\mathrm{p}=0.0167)$, but not when comparing males $(\mathrm{p}=0.0556)$. However, the overall genotype effect recapitulated what was seen in the zero maze and light-dark exploration assays, with $\operatorname{Scn} 2 a^{E /+}$ females spending an average of $10.1 \pm 1.2 \%$ of test time in the center zone and WT females averaging $6.27 \pm 0.9 \%$ of time (Figure $8 \mathrm{C}$ ).

Data from our initial set of behavioral assays suggested that $\operatorname{Scn} 2 a^{E /+}$ mice showed lower anxiety-like behavior compared to WT controls. To further assess these behavioral abnormalities in the context of a more specific behavior involving novel objects, we used a marble burying assay. Both $\operatorname{Scn} 2 a^{E /+}$ males and females buried significantly fewer marbles compared to WT controls (males, WT: $13 \pm 1, \operatorname{Scn} 2 a^{E /+}: 5 \pm 2, \mathrm{p}=0.0019$; females, WT: $13 \pm 2, \operatorname{Scn} 2 a^{E /+}: 2 \pm 1, \mathrm{p}$ $<0.0001$; Figure 8D). Early on, it became apparent that some animals were not burying the marbles and a limited number of subsequent trials were video recorded. We observed normal exploratory behavior in recordings where animals did not bury the marbles, suggesting that the observed genotype effect on marble burying was due to lower anxiety-like behavior rather than inactivity.

Enhanced rotarod performance in Scn $2 a^{K 1422 E}$ male mice. Movement disorders have been reported in some children with $S C N 2 A$-associated infantile epileptic encephalopathy (Sanders et al., 2018) and deficits in motor function could potentially confound results from other behavioral assays. Therefore, we used an accelerating rotarod assay to evaluate motor coordination and balance in $\operatorname{Scn} 2 a^{E /+}$ mice compared to WT controls at 9 weeks of age. For each subject, latency to fall was measured for three trials and daily performance was assessed by averaging across trials. Two-way repeated measures ANOVA showed significant main effects of test day and 
genotype when comparing average latency to fall between $\operatorname{Scn} 2 a^{E /+}$ males and WT controls (Table 2). Scn $2 a^{E /+}$ males spent significantly more time on the rotarod compared to WT males by the third day of testing $(\mathrm{p}=0.0106)$. On day three of testing, average latency to fall was $121 \pm 6$ sec for WT males and $152 \pm 7 \mathrm{sec}$ for $S c n 2 a^{E /+}$ males (Figure 8E). Two-way repeated measures ANOVA only showed a significant main effect of test day when comparing $\operatorname{Scn} 2 a^{E /+}$ and WT females (Table 2). These data indicate that basic motor function in $\operatorname{Scn} 2 a^{E /+}$ remains intact.

Altered social behavior in Scn $2 a^{K 1422 E}$ mice. As previously noted, ASD or features of ASD are frequently reported in children with $S C N 2 A$ variants, including SCN2A-p.K1422E (Sundaram et al., 2013). Social behavior deficits are a common feature of ASD (American Psychiatric Association, 2013) and have been extensively studied in animal models of ASD-related gene disruptions (Silverman et al., 2010; Barak and Feng, 2016). We used a three-chamber assay, which takes advantage of innate preferences for novel social interactions, to evaluate social behavior in Scn $2 a^{E /+}$ mice compared to WT controls at 10 weeks of age. During the sociability phase, time spent sniffing either a novel object (empty wire cup) or an unfamiliar mouse was measured (Figure 9A). Two-way ANOVA comparing average sniffing time between $S c n 2 a^{E /+}$ males and WT controls during the sociability phase showed a significant main effect of target and a significant interaction between target and genotype (Table 2). On average, $S c n 2 a^{E /+}$ males spent significantly more time $(132.6 \pm 8.3 \mathrm{sec})$ sniffing an unfamiliar mouse compared to WT $(93.3 \pm 12.7 \mathrm{sec}$; Figure 9A). Two-way ANOVA showed only a significant main effect of target when comparing average sniffing time between $\operatorname{Scn} 2 a^{E /+}$ females and WT controls during the sociability phase (Table 2). These data suggest that preference for social interactions is intact for both male and female $S c n 2 a^{E /+}$ mice, while $S c n 2 a^{E /+}$ males, but not females, display a greater 
preference for social interactions compared to WT. During the social novelty phase, time spent sniffing either a familiar mouse or an unfamiliar mouse was measured (Figure 9B). Two-way ANOVA showed significant main effects of target and genotype when comparing average sniffing time between $S c n 2 a^{E /+}$ and WT males during the social novelty phase (Table 2). On average, $S c n 2 a^{E /+}$ males spent significantly more time $(77.1 \pm 5.7 \mathrm{sec})$ sniffing an unfamiliar mouse compared to WT males $(48.8 \pm 8.7 \mathrm{sec}$; Figure $9 B)$. Two-way ANOVA also showed significant main effects of target and genotype when comparing average sniffing time between $\operatorname{Scn} 2 a^{E /+}$ females and WT controls during the social novelty phase (Table 2). On average, $\operatorname{Scn} 2 a^{E /+}$ females spent $61.9 \pm 7.7$ sec sniffing an unfamiliar mouse, while WT females spent $41.6 \pm 4.5 \mathrm{sec}$ sniffing an unfamiliar mouse (Figure 9B). These data suggest that preference for social novelty is intact for both male and female $\operatorname{Scn} 2 a^{E /+}$ mice, and that $\operatorname{Scn} 2 a^{E /+}$ males, but not females, display a greater preference for social novelty compared to WT.

Lower olfactory dishabituation to social odors in Scn $2 a^{K 1422 E}$ mice. The three-chamber assay described above measures sniffing time as the variable of interest and could therefore be affected by deficits in olfactory discrimination. We used an olfactory habituation/dishabituation assay to evaluate olfactory discrimination in $\operatorname{Scn} 2 a^{E /+}$ mice compared to WT controls at 11 weeks of age. Each odorant (water, almond extract, banana extract, same sex urine, opposite sex urine) was presented for three consecutive trials before proceeding to the next odor in the sequence for a total of 15 trials. Time spent sniffing the odor delivery apparatus was measured for each trial and compared between genotypes. Habituation refers to a decrease in sniffing behavior upon repeated presentation of an odor, while dishabituation refers to an increase in sniffing behavior upon presentation of a novel odor. Qualitatively, olfactory discrimination and preference for 
social odors appear to be intact for both male and female $\operatorname{Scn} 2 a^{E /+}$ mice (Figure 10A). However, the amount of time $\operatorname{Scn} 2 a^{E /+}$ males spent sniffing same sex urine during the first two presentations was over 50\% lower than WT males ( $\mathrm{p}=0.0005$ and $\mathrm{p}=0.0307$, respectively). During the first presentation, average sniffing time was $42.3 \pm 3.3 \mathrm{sec}$ for WT males and $18.8 \pm$ $3.4 \mathrm{sec}$ for $\operatorname{Scn} 2 a^{E /+}$ males, while average sniffing time for the second presentation was $26.3 \pm$ $8.9 \mathrm{sec}$ for WT males and $8.9 \pm 2.1 \mathrm{sec}$ for $\operatorname{Scn} 2 a^{E /+}$ males (Figure 10A). Scn $2 a^{E /+}$ females also spent significantly less time sniffing same sex urine compared to WT females, but only during the first presentation $(\mathrm{p}=0.0045)$. Average sniffing time was $46.3 \pm 4.6 \mathrm{sec}$ for WT females and $19.9 \pm 4.2 \sec$ for $\operatorname{Scn} 2 a^{E /+}$ females (Figure 10A).

The three-chamber and olfactory habituation/dishabituation assays suggest that olfactoryguided behavior is altered in $\operatorname{Scn} 2 a^{E /+}$ mice and that these effects were more pronounced for social odors. In order to exclude the possibility that olfaction was globally affected, we used a buried food task to compare a separate cohort of $\operatorname{Scn} 2 a^{E /+}$ mice and WT controls at 9 weeks of age. Task performance was evaluated by measuring the amount of time it took for food-deprived subjects to locate a hidden food stimulus. Both males and female $S c n 2 a^{E /+}$ mice performed as well as sex-matched WT controls (males, WT: $44.86 \pm 11.58 \mathrm{sec}, \operatorname{Scn} 2 a^{E /+}: 32.46 \pm 9.95 \mathrm{sec}, \mathrm{p}=$ 0.7471; females, WT: $89.00 \pm 44.31 \mathrm{sec}, \operatorname{Scn} 2 a^{E /+}: 161.7 \pm 70.02, \mathrm{p}=0.2927$; Figure 10B), indicating that olfaction remains intact.

\section{Discussion}

$S C N 2 A$ variants have been associated with a wide range of NDD that reflect a complex spectrum of phenotypes (Sanders et al., 2018). Significant attention has been given to the far ends of this phenotypic spectrum, establishing a framework in which $S C N 2 A$ missense variants that result in GoF effects are associated with infantile epileptic encephalopathy, while PTVs that result in LoF 
effects are associated with ID/ASD that sometimes present with co-morbid seizures starting later in life (Shi et al., 2012; Brunklaus et al., 2014; Ben-Shalom et al., 2017; Wolff et al., 2017; Begemann et al., 2019). More recently, attempts have been made to further refine the genotypephenotype relationships of $S C N 2 A$-related disorders (Crawford et al., 2021), an effort that can be supported by animal models of unusual variants. Here, we focused on the variant $S C N 2 A$ p.K1422E, which we and others have shown alters ion channel selectivity in heterologous expression systems (Heinemann et al., 1992; Schlief et al., 1996). We further characterized cellular and behavioral phenotypes associated with this unique variant in a newly generated mouse model $\left(S c n 2 a^{K 1422 E}\right)$. Excitatory neurons in allocortex and neocortex from $S c n 2 a^{E /+}$ mice displayed a novel TTX-insensitive current and aberrant calcium influx that occurs during the rising phase of the AP localized to Nav1.2-rich regions of the AIS, indicating that the variant channel is functionally expressed in these cells. $\operatorname{Scn} 2 a^{E /+}$ mice also display neurological/neurobehavioral phenotypes, including infrequent spontaneous seizures, lower anxiety-like behavior, and alterations in olfactory-guided behavior. These phenotypes are similar yet distinct from those observed in other models of Scn2a dysfunction, consistent with altered Nav1.2 ion selectivity having mixed effects on channel function.

Effects of altered $\mathrm{Na}_{V} 1.2$ ion selectivity on neuronal function. Vertebrate voltage-gated sodium channels contain four highly conserved residues (DEKA) that confer selectivity for sodium (Dudev and Lim, 2014; Sanders et al., 2018). These channels evolved from a primordial channel with mixed selectivity, where the selectivity filter has a glutamic acid (E) substituted for lysine (K) in the $3^{\text {rd }}$ transmembrane domain (Zhou et al., 2004; Stephens et al., 2015). Thus, the K1422E variant can be seen as an evolutionary reversion at the selectivity filter (Gur Barzilai et 
al., 2012; Zakon, 2012). Consistent with previous work on rat Nav1.2 channels in Xenopus oocytes (Heinemann et al., 1992), we show that substitution of glutamic acid for lysine at position 1422 (DEKA to DEEA) in human Nav1.2 confers calcium permeability not evident in wild-type human Nav1.2 channels (Figure 1B).

Based on modeling of biophysical data here and in previous reports (Heinemann et al., 1992), we estimated relative permeabilities of $\mathrm{K} 1422 \mathrm{E}$ channels to be $\mathrm{Na}^{+}, \mathrm{K}^{+}$, and $\mathrm{Ca}^{2+}$ to be 1:0.7:0.8. Interestingly, some invertebrates express more primitive Nav1 channels containing the DEKA selectivity filter that nevertheless appear to have some calcium permeability (Meves and Vogel, 1973). This suggests that additional aspects of Nav1 evolution, including changes to other residues lining the pore (Kawai et al., 2021), may confer additional ion selectivity/permeability properties. Consistent with this, recurrent $S C N 2 A$ missense variants that affect pore-adjacent arginine residues R397 and R973 eliminate permeation altogether (Ben-Shalom et al., 2017). Future functional studies should therefore include measures of cation permeability in addition to standard kinetic and voltage dependence assays when considering variants affecting the pore domain.

Before the existence of sodium channels, cellular depolarization was mediated by calcium-selective channels or nonselective cation channels (Gur Barzilai et al., 2012; Zakon, 2012). As such, changes in membrane potential were linked to alterations in intracellular calcium and associated downstream calcium-dependent signaling. Sodium channels are thought to have evolved in part to allow cells to separate changes in voltage from calcium signaling. What effects, then, could arise from recombining these processes in Nav1.2 channels? Within the AIS, we show that calcium influx occurs both before and after the peak of the AP in K1422Eexpressing neurons (Figure 5B-D). This contrasts with typical conditions where sodium and 
calcium influx are separated on the rising and falling phases of the AP, respectively (Filipis and Canepari, 2021; Lipkin et al., 2021, but see Hanemaaijer et al., 2020). This additional calcium influx could have myriad effects on AIS function, as many AIS components are regulated directly by calcium or through calcium/calmodulin interactions (Wen and Levitan, 2002; Kim et al., 2004; Swain et al., 2015; Clarkson et al., 2017). Additionally, excess calcium influx could affect cellular processes beyond the AIS as Nav1.2 channels are also expressed in the somatodendritic domain and throughout the axons of unmyelinated neurons (Gong et al., 1999; Vacher et al., 2008; Lorincz and Nusser, 2010; Zhu et al., 2020). During high-frequency activity, intracellular sodium concentrations can exceed $50 \mathrm{mM}$ in some nerve terminals (Zhu et al., 2020). Excess calcium influx through K1422E channels could therefore affect transmitter release and short-term presynaptic plasticity (Stanley, 2016; Burke and Bender, 2019). Nav1.2 channels also influence dendritic excitability in neocortex (Spratt et al., 2019). Thus, excess calcium may affect dendritic integration/plasticity, depending on the location of these channels relative to synaptic inputs.

\section{Neurological and neurobehavioral phenotypes associated with the K1422E variant. Scn $2 a$}

knockout models have been used to study phenotypes associated with LoF effects on Nav1.2 (Léna and Mantegazza, 2019; Spratt et al., 2019; Tatsukawa et al., 2019; Indumathy et al., 2021). As previously discussed, some properties of $\operatorname{Scn} 2 a^{E /+}$ neurons are similar to those observed in Nav1.2 knockouts (reduced AP speed), while others are unique (calcium flux). Correlated with these complex channel properties are neurological/neurobehavioral phenotypes in $\operatorname{Scn} 2 a^{E /+}$ mice that are similarly mixed. 
EEG recording has been used to evaluate neurological phenotypes in $\operatorname{Scn} 2 a^{+/}$mice with conflicting results. Ogiwara and colleagues (2018) described spike-and-wave discharges characteristic of absence epilepsy in $\operatorname{Scn} 2 a^{+/-}$mice, while other groups reported no observable seizures in $S c n 2 a^{+/-}$mice (Mishra et al., 2017). However, this may be due to differences in age and/or strain that can affect spike-and-wave discharges and seizure susceptibility (Bergren et al., 2005; Connor et al., 2005; Martin et al., 2007; Bessaih et al., 2012; Frankel et al., 2014; Kehrl et al., 2014; Miller et al., 2014; Calhoun et al., 2016). We performed video-EEG recordings in $\operatorname{Scn} 2 a^{E /+}$ mice for a minimum of 96 hours per animal, far longer than what has been reported for $S c n 2 a$ knockouts, and observed rare spontaneous seizures localized to parieto-occipital cortex. To date, spontaneous seizures have not been described in any $\operatorname{Scn} 2 a$ knockout models. In order to further probe seizure susceptibility in $\operatorname{Scn} 2 a^{E /+}$ mice, we induced seizures using flurothyl. Although latency to the first seizure stage of myoclonic jerk did not differ from WT, Scn $2 a^{E /+}$ mice had longer latency to GTCS. This suggests that threshold for seizure generation is not altered, but that $S c n 2 a^{E /+}$ mice may be resistant to seizure spread, which would be consistent with the localized spontaneous seizures. Paradoxical seizure thresholds have been observed in other mouse epilepsy models (Amador et al., 2020; Sah et al., 2020) and may reflect the mechanism by which flurothyl, a GABAA antagonist, induces seizures (Ferland, 2017). Interestingly, we also observed a reproducible non-unimodal distribution of GTCS latencies in $\operatorname{Scn} 2 a^{E /+}$ females compared to WT. One possible explanation is a genotype-dependent interaction with fluctuating sex hormones and/or neurosteroids, which have previously been linked to altered seizure susceptibility in rodents (Woolley, 2000; Scharfman et al., 2005; Gangisetty and Reddy, 2010; Kight and McCarthy, 2014; Joshi and Kapur, 2019; Li et al., 2020). 
Behavioral abnormalities reported in $\operatorname{Scn} 2 a^{+/-}$mice vary across research groups and may reflect differences in methodological practices (e.g. age or background strain), as well as inherent variability of behavioral data (Anon, 2009; Saré et al., 2021). We observed lower anxiety-like behavior in $\operatorname{Scn} 2 a^{E /+}$ mice across three exploration assays (zero maze, light-dark exploration, and open field) and an active marble burying task. This is similar to what has been reported in $S c n 2 a^{+/-}$mice (Léna and Mantegazza, 2019; Spratt et al., 2019; Tatsukawa et al., 2019). Scn2a $a^{E /+}$ mice also displayed hyper-social behavior in a three-chamber assay, while inconsistent effects on social behavior have been reported in $S c n 2 a^{+/-}$mice (Tatsukawa et al., 2019; Indumathy et al., 2021). Although ASD is typically associated with social behavior deficits (Barak and Feng, 2016), hyper-social behavior has been reported in other ASD-associated genetic mouse models (Chao et al., 2010; Mejias et al., 2011). This highlights the heterogeneity of ASD-associated phenotypes and complexity of modeling human social behavior in animals. In particular, mouse social behavior is guided by olfaction and olfactory function must be considered when interpreting assay results. Direct assessment of olfaction in $\operatorname{Scn} 2 a^{E /+}$ mice revealed intact discrimination for both social and non-social odors, but lower dishabituation to same-sex social odors compared to WT. This apparent contradiction with the hyper-social behavior observed in the three-chamber assay, which evaluates interactions with a target mouse rather than an odorsoaked cotton-swab, suggests that altered social behavior in $S c n 2 a^{K 1422 E}$ mice occurs downstream of olfactory perception.

Consistent with mixed effects of K1422E on channel function, $S c n 2 a^{K 1422 E}$ mice present with phenotypes that overlap $\operatorname{Scn} 2 a$ haploinsufficiency, as well as unique epilepsy-related phenotypes that are not observed in loss-of-function models. This combination of phenotypes 
bioRxiv preprint doi: https://doi.org/10.1101/2021.07.19.452930; this version posted July 19, 2021. The copyright holder for this preprint (which was not certified by peer review) is the author/funder, who has granted bioRxiv a license to display the preprint in perpetuity. It is made available under aCC-BY-NC-ND 4.0 International license.

within a single model underscores how $S c n 2 a^{K 1422 E}$ mice can serve as a useful platform to investigate phenotypic complexity of $S C N 2 A$-associated disorders. 
bioRxiv preprint doi: https://doi.org/10.1101/2021.07.19.452930; this version posted July 19, 2021. The copyright holder for this preprint (which

was not certified by peer review) is the author/funder, who has granted bioRxiv a license to display the preprint in perpetuity. It is made available under aCC-BY-NC-ND 4.0 International license.

\section{Table 1. List of Primers and Probes}

\begin{tabular}{|l|l|l|}
\hline Assay & Description & Sequence \\
\hline \multirow{3}{*}{ Founder Screening PCR } & Primer 1 & 5'-AGCTCATCTATCACCTTGAACC \\
\cline { 2 - 3 } & Primer 2 & 5'-AAAGAAACGAATCCCCAACAAAA \\
\hline \multirow{3}{*}{ Genotyping Scn $\boldsymbol{2 a}^{\text {K1422E }}$} & Primer 1 & 5'-GTGGTAGAAATATCCAGAATGCTTCCC \\
\cline { 2 - 3 } & Primer 2 & 5'-CTTGAGTCAACAGCTGCATACATGA \\
\cline { 2 - 3 } & Probe 1 (WT allele) & 5'-VIC-CATCCATCCTTTAAATGT-NFQ \\
\cline { 2 - 3 } & Probe 2 (mutant allele) & 5'-FAM-TCCATCCTTCAAATGT-NFQ \\
\hline
\end{tabular}

Abbreviations: FAM, FAM reporter dye; VIC, VIC reporter dye; NFQ, non-fluorescent quencher 
bioRxiv preprint doi: https://doi.org/10.1101/2021.07.19.452930; this version posted July 19, 2021. The copyright holder for this preprint (which was not certified by peer review) is the author/funder, who has granted bioRxiv a license to display the preprint in perpetuity. It is made available under aCC-BY-NC-ND 4.0 International license.

Table 2. Statistical Comparisons

\begin{tabular}{|c|c|c|c|c|}
\hline Figure & Comparison & Test & Value & Post Hoc \\
\hline \multirow{3}{*}{1} & Sodium Current Density at $-10 \mathrm{mV}(\mathbf{C})$ & Student's t-test & $\mathrm{p}=0.0033$ & $\mathrm{n} / \mathrm{a}$ \\
\hline & Sodium Current Reversal Potential (D) & Student's t-test & $\mathrm{p}=0.0109$ & $\mathrm{n} / \mathrm{a}$ \\
\hline & Calcium Current Density at $-10 \mathrm{mV}(\mathbf{E})$ & Student's t-test & $\mathrm{p}<0.0001$ & $\mathrm{n} / \mathrm{a}$ \\
\hline \multirow{2}{*}{3} & Scn2 $a^{K 1422 E}$ Expression (D) & Student's t-test & $\mathrm{p}=0.6295$ & $\mathrm{n} / \mathrm{a}$ \\
\hline & $\mathrm{Na}_{V} 1.2-\mathrm{K} 1422 \mathrm{E}$ Expression $(\mathbf{E})$ & Student's t-test & $\mathrm{p}=0.2937$ & $\mathrm{n} / \mathrm{a}$ \\
\hline \multirow{3}{*}{4} & Total Sodium Current Reversal Potential (D) & Student's t-test & $\mathrm{p}=0.0364$ & $\mathrm{n} / \mathrm{a}$ \\
\hline & TTX-Sensitive Current Reversal Potential (D) & Student's t-test & $\mathrm{p}=0.0006$ & $\mathrm{n} / \mathrm{a}$ \\
\hline & TTX-Insensitive Current Reversal Potential (D) & Student's t-test & $\mathrm{p}=0.6964$ & $\mathrm{n} / \mathrm{a}$ \\
\hline 5 & Peak Action Potential Speed (D) & Student's t-test & $\mathrm{p}=0.01$ & $\mathrm{n} / \mathrm{a}$ \\
\hline \multirow{2}{*}{6} & Calcium Transient Amplitude (C) & Student's t-test & $\mathrm{p}=0.014$ & $\mathrm{n} / \mathrm{a}$ \\
\hline & Calcium Transient Onset (D) & Student's t-test & $\mathrm{p}<0.001$ & $\mathrm{n} / \mathrm{a}$ \\
\hline \multirow{6}{*}{7} & Male GTCS Flurothyl $(\mathbf{E})$ & Welch's t-test & $\mathrm{p}<0.0001$ & $\mathrm{n} / \mathrm{a}$ \\
\hline & Female GTCS Flurothyl $(\mathbf{E})$ & $\begin{array}{l}\text { Kolmogorov-Smirnov } \\
\text { test }\end{array}$ & $\mathrm{p}=0.0282$ & $\mathrm{n} / \mathrm{a}$ \\
\hline & Male MJ Flurothyl $(\mathbf{F})$ & Student's t-test & $\mathrm{p}=0.8813$ & $\mathrm{n} / \mathrm{a}$ \\
\hline & Male Time for Seizure Progression $(\mathbf{F})$ & Mann-Whitney test & $\mathrm{p}<0.0001$ & $\mathrm{n} / \mathrm{a}$ \\
\hline & Female MJ Flurothyl $(\mathbf{F})$ & Mann-Whitney test & $\mathrm{p}=0.7126$ & $\mathrm{n} / \mathrm{a}$ \\
\hline & Female Time for Seizure Progression $(\mathbf{F})$ & $\begin{array}{l}\text { Kolmogorov-Smirnov } \\
\text { test }\end{array}$ & $\mathrm{p}=0.0350$ & $\mathrm{n} / \mathrm{a}$ \\
\hline \multirow{10}{*}{8} & Male Zero Maze $(\mathbf{A})$ & Student's t-test & $\mathrm{p}=0.0023$ & $\mathrm{n} / \mathrm{a}$ \\
\hline & Female Zero Maze (A) & Welch's t-test & $\mathrm{p}=0.0297$ & $\mathrm{n} / \mathrm{a}$ \\
\hline & Male Light-Dark Exploration (B) & Student's t-test & $\mathrm{p}=0.0367$ & $\mathrm{n} / \mathrm{a}$ \\
\hline & Female Light-Dark Exploration (B) & Mann-Whitney test & $\mathrm{p}=0.0367$ & $\mathrm{n} / \mathrm{a}$ \\
\hline & Male Open Field $(\mathbf{C})$ & Mann-Whitney test & $\mathrm{p}=0.0556$ & $\mathrm{n} / \mathrm{a}$ \\
\hline & Female Open Field $(\mathbf{C})$ & Mann-Whitney test & $\mathrm{p}=0.0167$ & $\mathrm{n} / \mathrm{a}$ \\
\hline & Male Marble Burying (D) & Mann-Whitney test & $\mathrm{p}=0.0019$ & $\mathrm{n} / \mathrm{a}$ \\
\hline & Female Marble Burying (D) & Mann-Whitney test & $\mathrm{p}<0.0001$ & $\mathrm{n} / \mathrm{a}$ \\
\hline & Male Rotarod $(\mathbf{E})$ & $\begin{array}{l}\text { Two-way repeated } \\
\text { measures ANOVA }\end{array}$ & $\begin{array}{l}\mathrm{F}(1.511,34.76)=8.450, \mathrm{p}=0.0022 \\
\text { (Main Effect: Test Day) } \\
\mathrm{F}(1,23)=10.18, \mathrm{p}=0.0041 \\
\text { (Main effect: Genotype) }\end{array}$ & Sidak’s \\
\hline & Female Rotarod $(\mathbf{E})$ & $\begin{array}{l}\text { Two-way repeated } \\
\text { measures ANOVA }\end{array}$ & $\begin{array}{l}\mathrm{F}(1.594,36.65)=6.646, \mathrm{p}=0.0059 \\
\text { (Main effect: Test Day) } \\
\mathrm{F}(1,23)=1.249, \mathrm{p}=0.2752 \\
\text { (Main Effect: Genotype) }\end{array}$ & Sidak’s \\
\hline \multirow{4}{*}{9} & Male Three-chamber - Sociability (A) & $\begin{array}{l}\text { Two-way repeated } \\
\text { measures ANOVA }\end{array}$ & $\begin{array}{l}\mathrm{F}(1,24)=9.198, \mathrm{p}=0.0057 \\
(\text { Target } \mathrm{x} \text { Genotype) } \\
\mathrm{F}(1,24)=57.28, \mathrm{p}<0.0001 \\
\text { (Main effect: Target) }\end{array}$ & Sidak’s \\
\hline & Female Three-chamber - Sociability (A) & $\begin{array}{l}\text { Two-way repeated } \\
\text { measures ANOVA }\end{array}$ & $\begin{array}{l}\mathrm{F}(1,22)=35.17, \mathrm{p}<0.0001 \\
\text { (Main effect: Target) }\end{array}$ & Sidak's \\
\hline & Male Three-chamber - Social Novelty (B) & $\begin{array}{l}\text { Two-way repeated } \\
\text { measures ANOVA }\end{array}$ & $\begin{array}{l}\mathrm{F}(1,26)=19.02, \mathrm{p}=0.0002 \\
\text { (Main Effect: Target) } \\
\mathrm{F}(1,26)=11.85, \mathrm{p}=0.0020 \\
\text { (Main Effect: Genotype) }\end{array}$ & Sidak’s \\
\hline & Female Three-chamber - Social Novelty (B) & $\begin{array}{l}\text { Two-way repeated } \\
\text { measures ANOVA }\end{array}$ & $\begin{array}{l}\mathrm{F}(1,22)=9.145, \mathrm{p}=0.0062 \\
\text { (Main Effect: Target) } \\
\mathrm{F}(1,22)=6.081, \mathrm{p}=0.0219 \\
\text { (Main Effect: Genotype) }\end{array}$ & Sidak’s \\
\hline \multirow[t]{2}{*}{10} & Male Olfactory Habituation/Dishabituation & Multiple t-tests & $\begin{array}{l}p=0.0005(\text { Same Sex 1) } \\
p=0.0307(\text { Same Sex 2) }\end{array}$ & Holm-Sidak \\
\hline & Female Olfactory Habituation/Dishabituation & Multiple t-tests & $\mathrm{p}=0.0045($ Same Sex 1) & Holm-Sidak \\
\hline
\end{tabular}


A

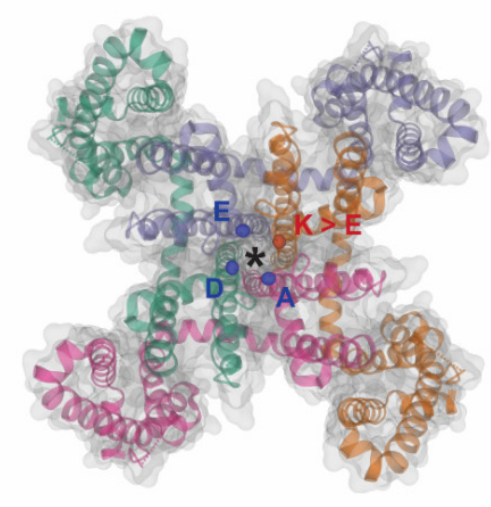

B
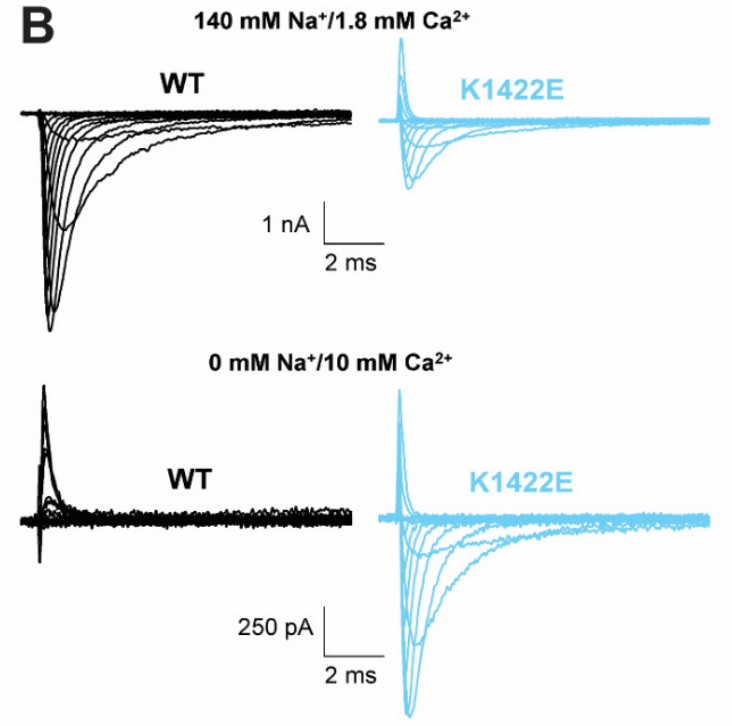

C

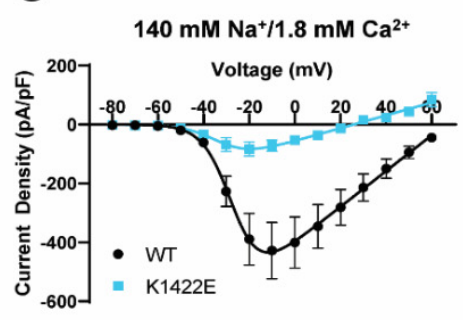

D

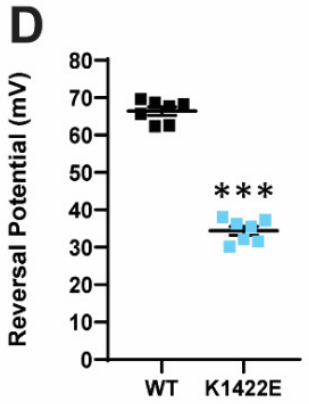

$\mathbf{E}$

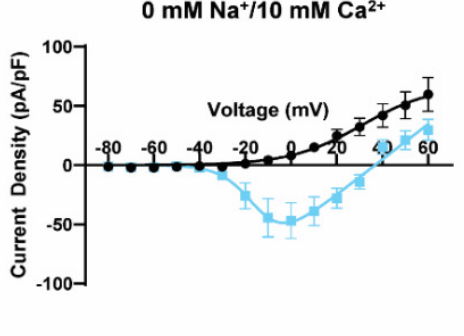

Figure 1. Heterologous expression of K1422E in HEK293T cells reveals altered ion selectivity. A) Homology model of voltage gated sodium channel alpha subunit (PDB 6MWA NavAb, residues 1-239). Four internally homologous domains coalesce with four-fold symmetry around an ion conducting pore denoted by an asterisk. The C $\alpha$ carbons from each residue (DEKA) of the highly conserved ion selectivity filter are represented by colored ellipses. The red ellipse denotes the C $\alpha$ carbon from the K1422 residue that is substituted for glutamate (E) in the Scn2a $a^{K 1422 E}$ model. B) Representative whole-cell sodium currents (top) and calcium currents (bottom) from WT (left) and K1422E (right) expressing cells. C) Summary current-voltage relationship of whole cells sodium current showing reduced sodium current density of K1422E at $-10 \mathrm{mV}$ $(\mathrm{p}=0.0033)$. D) Sodium reversal potential of WT and K1422E expressing cells $(\mathrm{p}<0.0001)$. E) Summary current-voltage relationship of whole cells calcium current showing increased calcium flux at $-10 \mathrm{mV}$ for K1422E ( $\mathrm{p}=0.0109$ ). All data are plotted as mean $\pm \mathrm{SEM}$ of $\mathrm{n}=7$ cells. 

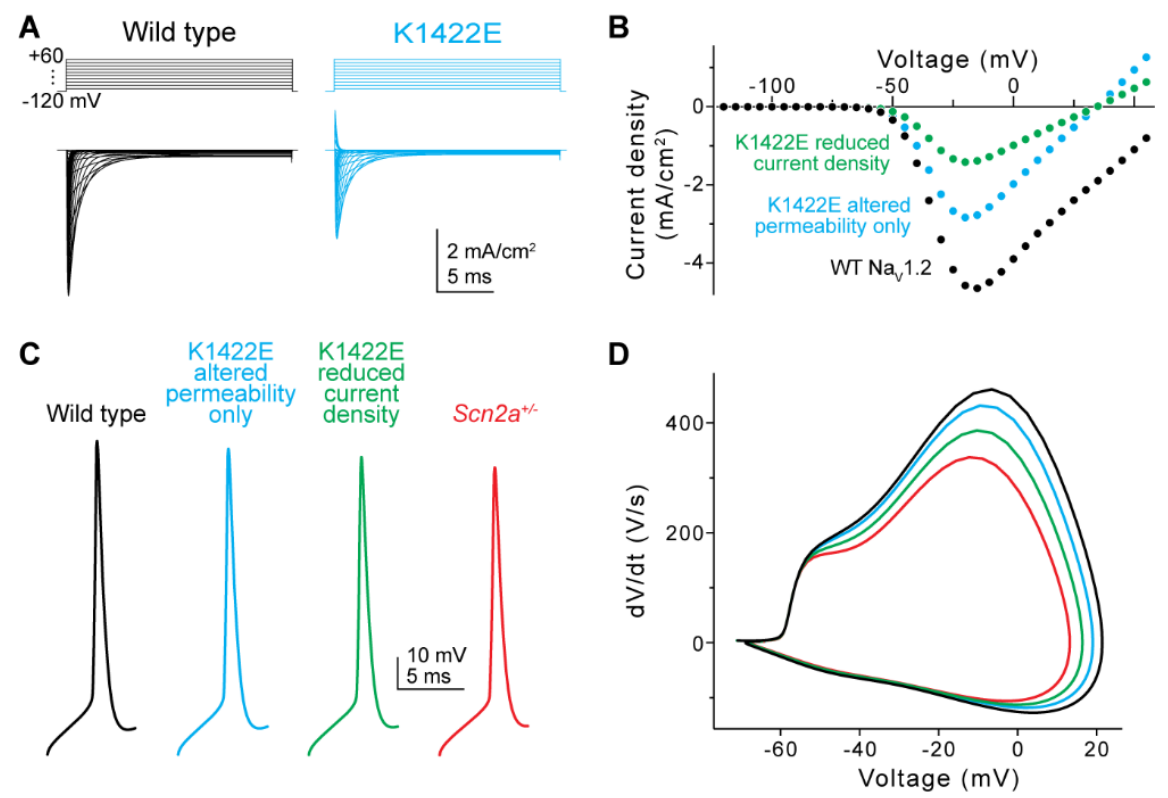

Figure 2. In silico simulations of K1422E in neocortical pyramidal cells. A) Current evoked from simulated WT (black) and K1422E (cyan) channels in response to voltage steps from -120 to $+60 \mathrm{mV}$ (10 mV increments). B) Current-voltage relationship for WT and K1422E channels. With altered permeability for $\mathrm{K}$ and $\mathrm{Ca}, \mathrm{K} 1422 \mathrm{E}$ current were reduced $\sim 50 \%$ compared to WT, with a reversal at $+33 \mathrm{mV}$ (cyan). Reductions in current density to mimic calcium antagonism were required to match empirical results (green, compare to Figure 1C). C) APs measured via a somatic electrode site in a model of a neocortical layer $5 \mathrm{~b}$ pyramidal cell (identical to Spratt et al., 2019). +/K1422E conditions were modeled with or without reduced current density (cyan, green) and compared to WT (+/-) and haploinsufficient conditions (+/-, red). D) Phase-plane plots of APs in C. 


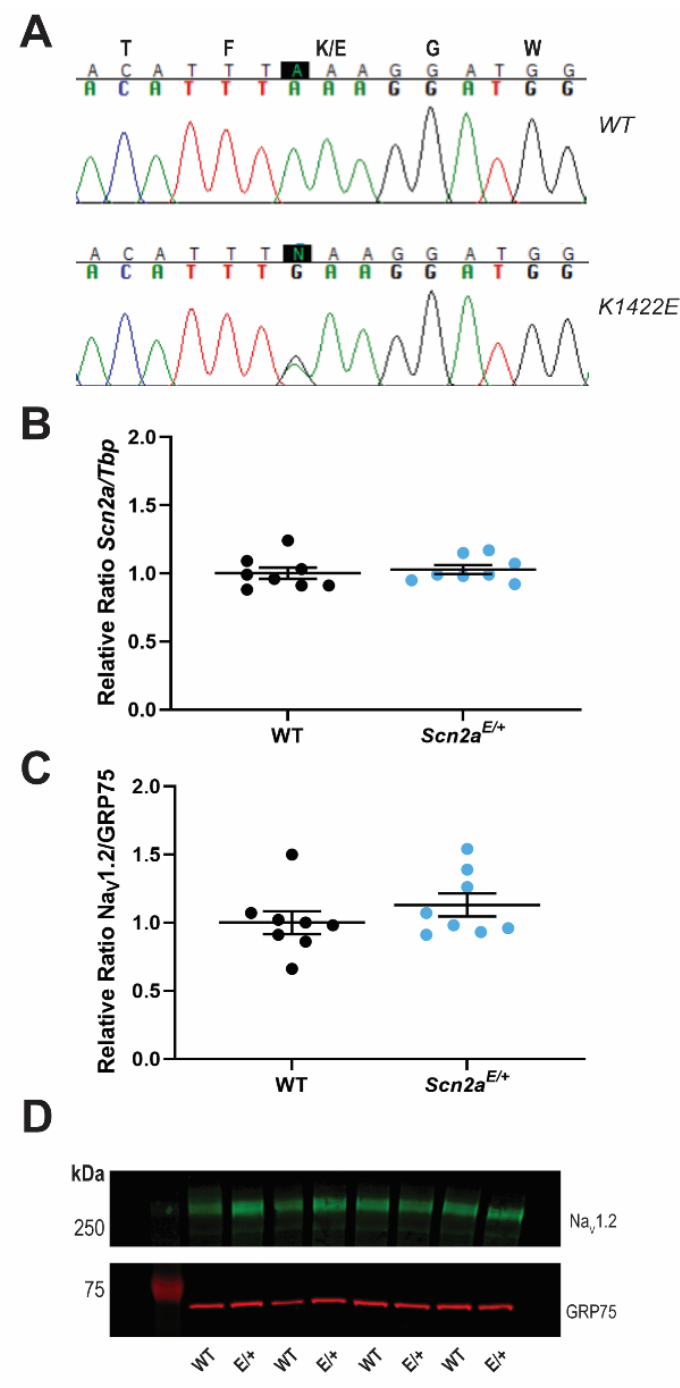

Figure 3. Generation and molecular characterization of $\operatorname{Scn} 2 a^{K 1422 E}$ mice. A) Sequencing chromatograms of Scn $2 a$ genomic PCR products with the first nucleotide of the K1422E codon highlighted in black. Top chromatogram from a WT littermate control mouse shows homozygosity for the WT nucleotide at the K1422E codon. Bottom chromatogram from a heterozygous $\operatorname{Scn} 2 a^{E /+}$ mouse shows heterozygosity for the single nucleotide change introduced by CRISPR/Cas9 genome editing and homology directed repair. B) Relative expression of whole brain $S c n 2 a$ transcript in WT and $S c n 2 a^{E /+}$ mice assayed by RT-ddPCR. Relative transcript levels are expressed as a ratio of $S c n 2 a$ concentration to Tbp concentration (normalized to WT average). There was no difference in transcript expression between genotypes $(\mathrm{p}=0.6295 ; \mathrm{n}=8$ mice per genotype). C) Relative expression of whole brain Nav1.2 protein in WT and $S c n 2 a^{E /+}$ mice assayed by immunoblotting. Quantification is expressed as a ratio of Nav1.2 immunofluorescence relative to GRP75/Mortalin (normalized to WT average). There was no difference in protein expression between genotypes $(p=0.2937 ; n=8$ mice per genotype). For both $\mathbf{B}$ and $\mathbf{C}$, circles represent samples from individual mice, horizontal lines represent mean, and error bars represent SEM. D) Representative immunoblot. Bands corresponding to Nav1.2 (MW: $260 \mathrm{kDa}$ ) are visualized in green (Alexa Fluor 790) while bands corresponding to GRP75 (MW: $73 \mathrm{kDa}$ ) are visualized in red (Alexa Fluor 680). 

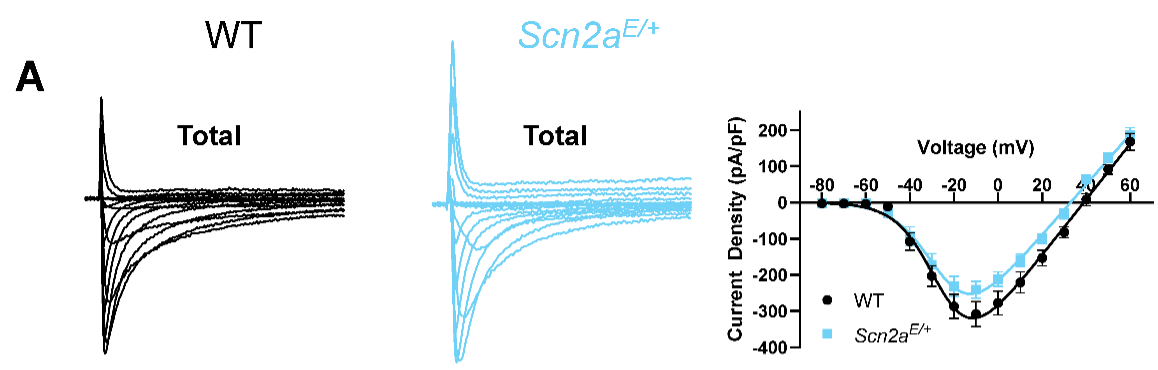

B
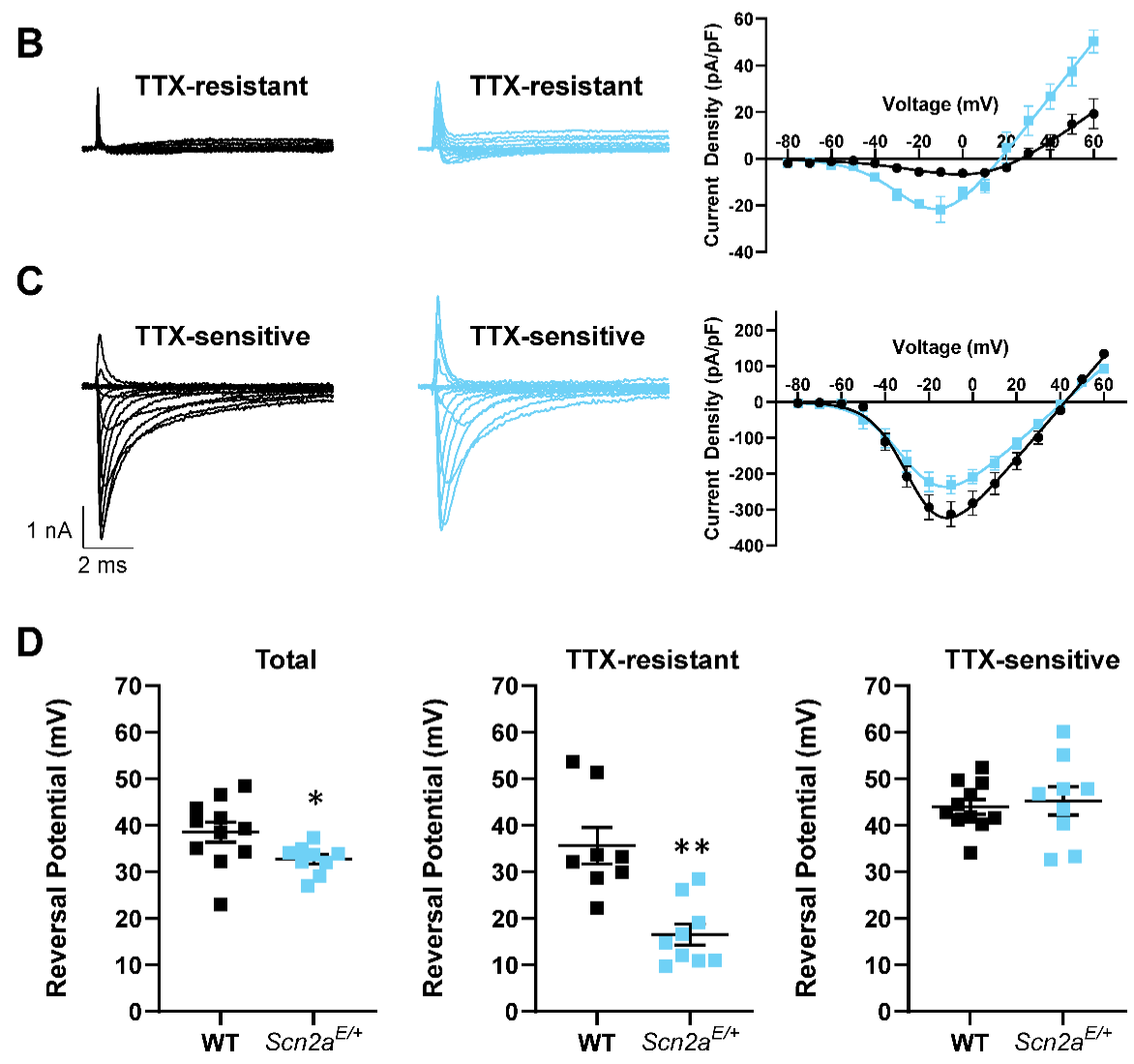

Figure 4. Whole-cell sodium currents of acutely isolated neuron. Representative whole-cell sodium currents and current voltage relationships of A) total sodium current, B) TTX-resistant currents, and C) TTX-sensitive currents from acutely dissociated hippocampal pyramidal neurons from WT and Scn $2 a^{E /+}$ mice, D) Sodium reversal potential of total sodium current (left, $\mathrm{p}=0.0364$ ), TTX-resistant current (middle, $\mathrm{p}=0.0006$ ), and TTX-sensitive currents (right, $\mathrm{p}=0.6964)$. All data are plotted as mean \pm SEM of $\mathrm{n}=8-11$ cells. 
A

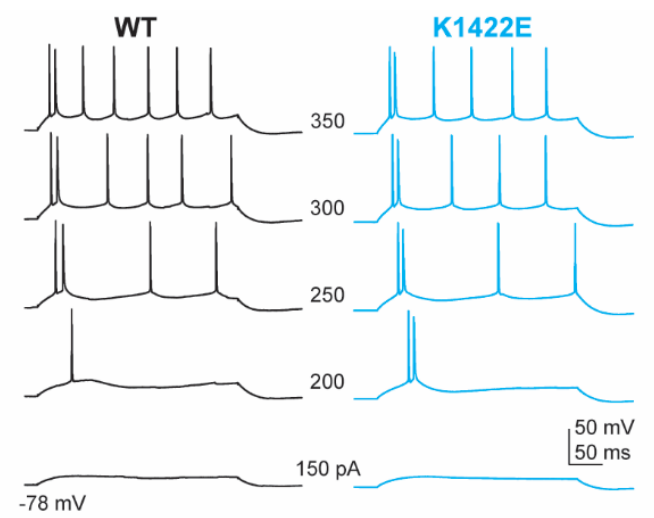

B

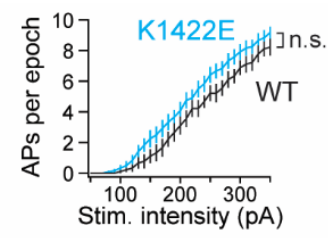

C

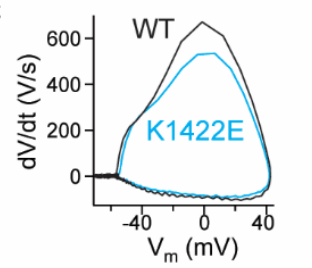

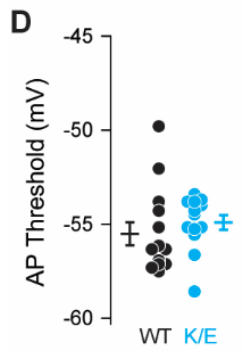
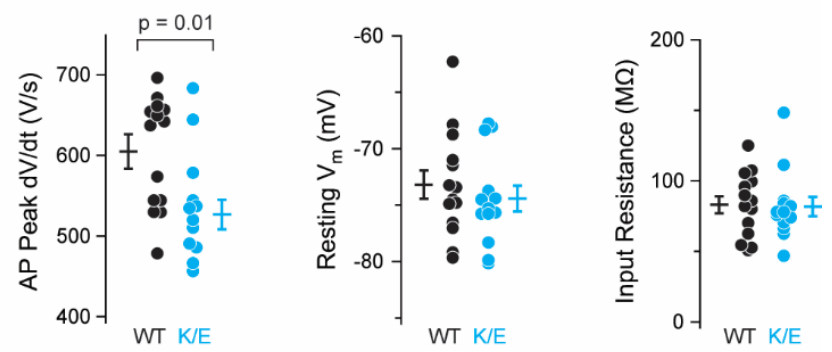

Figure 5. Scn $2 a^{K 1422 E}$ prefrontal pyramidal cell AP waveform has loss-of-function characteristics. A) Example whole-cell voltage response to somatic current injection in WT (black) and Scn2a $a^{E /+}$ (K1422E, cyan) neurons. Numbers between examples correspond to current injection amplitude. B) AP number per $300 \mathrm{~ms}$ current injection, color coded as in A. Bars are mean \pm SEM. $n=13$ cells each. C) Rheobase AP as dV/dt vs. voltage (phase-plane plot). Note reduction of peak dV/dt for $S c n 2 a^{E /+}$ cells compared to WT, indicative of loss-of-function in Nav1.2-mediated somatic depolarization. D) Summaries of AP waveform and intrinsic excitability characteristics. Circles are single cells, bars are mean $\pm \mathrm{SEM}$. Peak $\mathrm{dV} / \mathrm{dt}$ is reduced in $S c n 2 a^{E /+}$ cells, unpaired t-test. $\mathrm{n}=14 \mathrm{WT}, 13 S c n 2 a^{E /+}$ cells. 
A

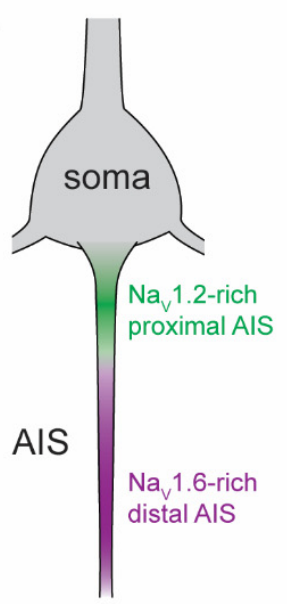

B

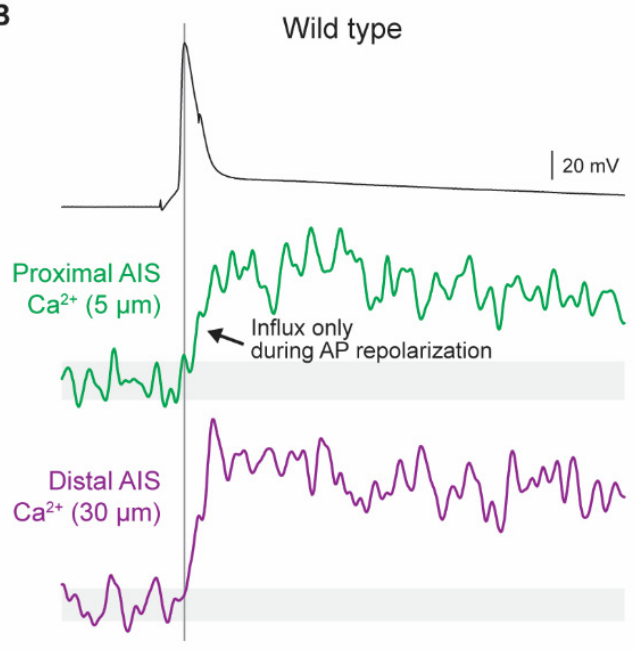

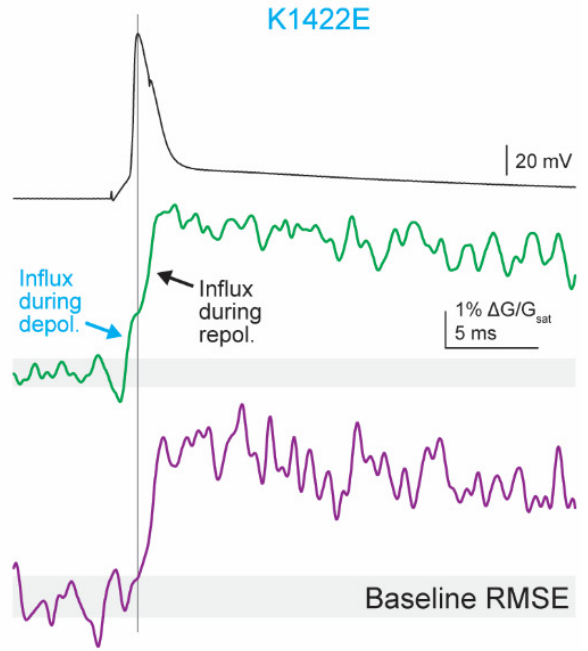

C

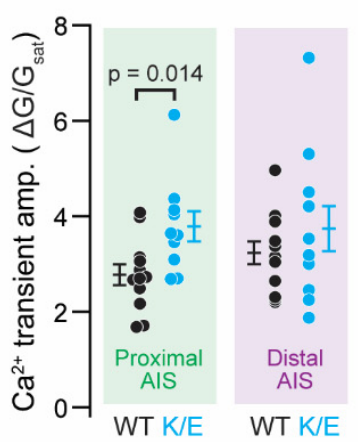

D

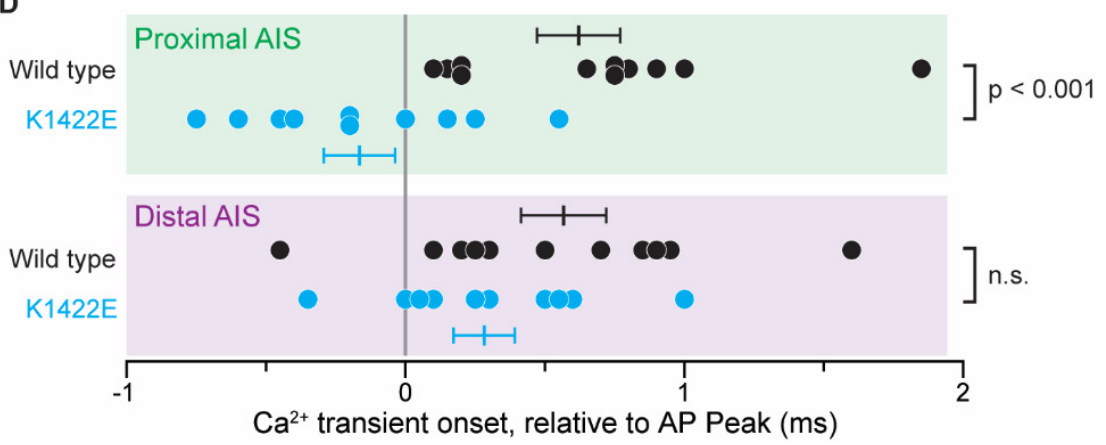

Figure 6. AP-evoked $\mathrm{Ca}^{2+}$ influx during the rising phase of the AP in the proximal AIS of $S c n 2 a^{E /+}$ cells. A) Pyramidal cell initial segments are enriched with Nav1.2 proximal to the soma and Nav1.6 more distal to the soma. Pointscan imaging was performed 5 and $30 \mu \mathrm{m}$ from the axon hillock, corresponding to Nav1.2 and Nav1.6-enriched regions, respectively. B) Examples of AP-evoked ( $2 \mathrm{nA}, 2$ ms stimulus; black, top) calcium transients imaged in pointscan mode in the proximal (green, middle) and distal (violet, bottom) AIS in WT (left) and $S c n 2 a^{E /+}$ cells (right). Vertical line is aligned to peak AP voltage. Grey shaded area encompasses imaging signal root-mean-squared error (RMSE) during baseline, before AP. Consistent deviation above this error value defines onset of $\mathrm{Ca}^{2+}$ transient. Note $\mathrm{Ca}^{2+}$ influx before AP peak in proximal AIS of K1422E condition, only. C) Amplitude of $\mathrm{Ca}^{2+}$ transient is higher in proximal AIS of $\operatorname{Scn} 2 a^{E /+}$ cells, consistent with influx from both local voltage-gated calcium channels and additional influx through K1422E Nav1.2 channels. Circles are single cells and bars are mean \pm SEM. p values from unpaired t-tests. D) $\mathrm{Ca}^{2+}$ transient onset occurs earlier in the proximal AIS of $S \mathrm{Cn} 2 a^{E /+}$ cells, consistent with $\mathrm{Ca}^{2+}$ influx through K1422E Nav1.2 channels. Display as in C. 
A

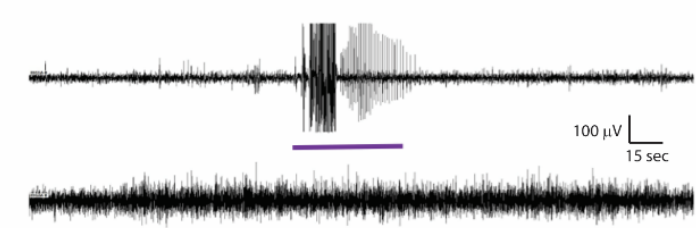

B

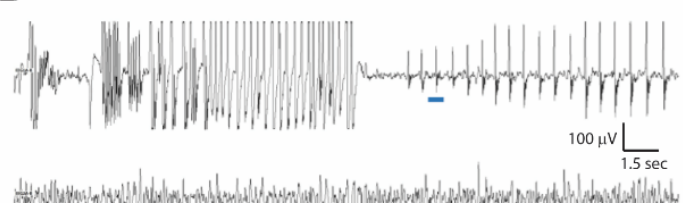

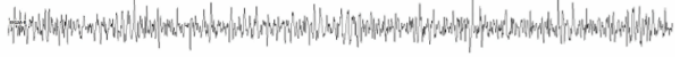

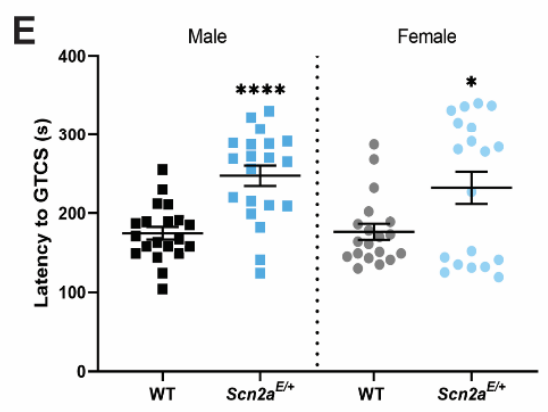

G

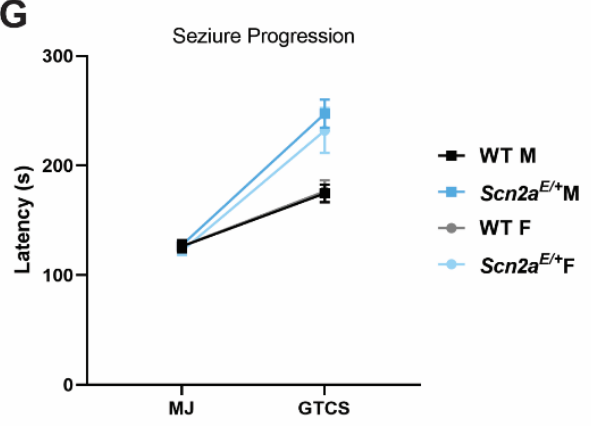

C

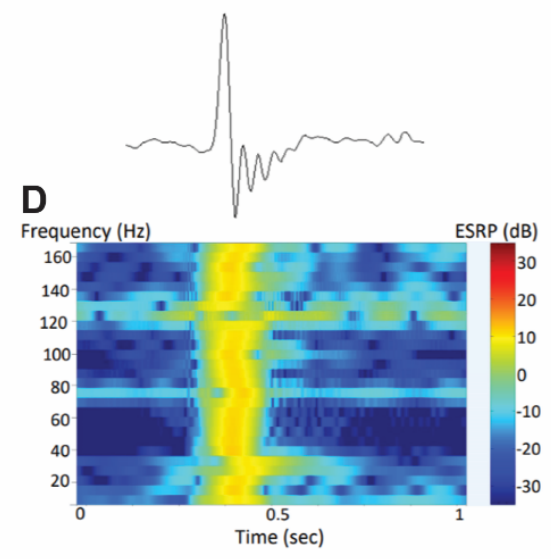

$\mathbf{F}$

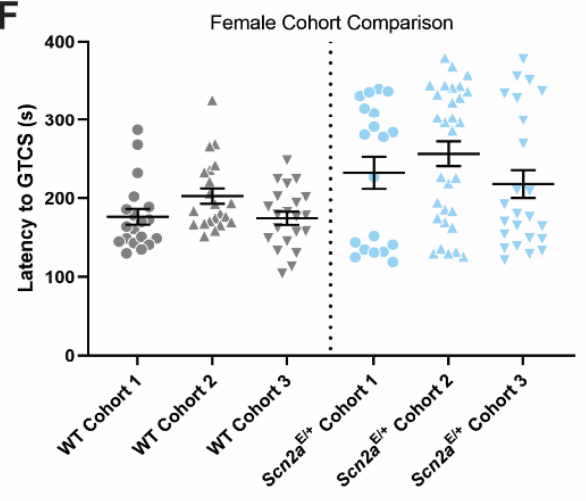

Figure 7. EEG abnormalities and altered susceptibility to induced seizures in $\operatorname{Scn} 2 a^{E /+}$ mice. A) Representative 5-minute epoch of EEG from $S c n 2 a^{E /+}$ mice. A localized seizure occurred as an abrupt onset of rhythmic $2 \mathrm{~Hz}$ sharp waves with overriding fast activity that evolve in amplitude and frequency for $\sim 45$ seconds before abruptly terminating with return to typical sleep background. B) 30-second epoch corresponding to the purple bar segment from A. The top line in both $\mathbf{A}$ and $\mathbf{B}$ corresponds to channel 1 (right posterior-left posterior) and second line is channel 2 (right anterior-left posterior). C) Example of an isolated high amplitude sharp wave with overriding fast activity corresponding to the blue bar segment in B. D) Power spectrum for the sharp wave in $\mathbf{C}$ showing elevated power in decibels across the 1-170 Hz frequency range at the time of discharge. E) Latency to flurothyl-induced GTCS in $\operatorname{Scn} 2 a^{E /+}$ mice compared to WT at 6-9 weeks of age. $\operatorname{Scn} 2 a^{E /+}$ males had an elevated threshold for flurothyl-induced seizures compared to WT (WT: $175 \pm 8 \mathrm{sec}, \operatorname{Scn} 2 a^{E /+}: 247 \pm 13 \mathrm{sec}, * * * * \mathrm{p}<0.0001$; Welch's t-test). $\operatorname{Scn} 2 a^{E /+}$ females also had an elevated threshold for flurothyl-induced seizures compared to WT (WT: $177 \pm 10 \mathrm{sec}, \operatorname{Scn} 2 a^{E /+}: 232 \pm 20 \mathrm{sec},{ }^{*} \mathrm{p}=0.0282$; Kolmogorov-Smirnov test). Symbols represent samples from individual mice, horizontal lines represent mean, and error bars represent 
SEM. F) Latency to first flurothyl-induced generalized tonic-clonic seizure (GTCS) in WT and $\operatorname{Scn} 2 a^{E+}$ female mice across multiple cohorts $(\mathrm{n}=19-30$ per genotype and cohort). Cohorts were evaluated at different times. Data from $\operatorname{Scn} 2 a^{E /+}$ females is abnormally distributed in all three cohorts compared to cohort-matched WT controls. G) Average latency to first myoclonic jerk (MJ) and GTCS, with connecting line depicting time of progression between stages. There was no genotype difference in latency to first MJ for both sexes (Table 2). However, progression between stages was slower for both male and female $S c n 2 a^{E /+}$ mice compared to WT (Males: $\mathrm{p}<0.0001$; Mann-Whitney test; Females: $\mathrm{p}=0.0350$, Kolmogorov-Smirnov test). Symbols represent group mean and error bars represent SEM; $n=19-20 /$ sex/genotype Males and females were analyzed separately. 

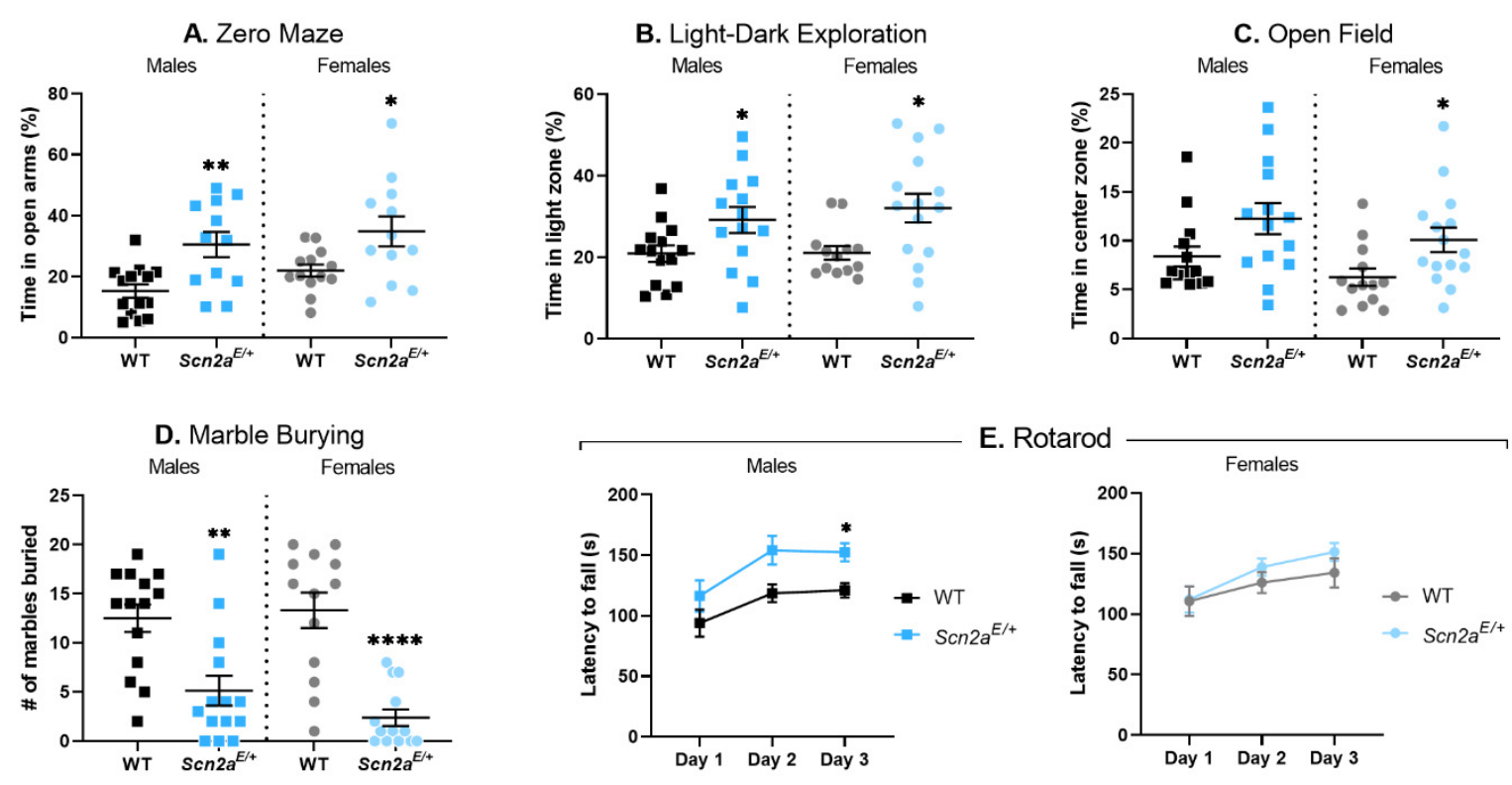

Figure 8. Altered anxiety-related behavior and rotarod performance in $\operatorname{Scn} 2 a^{E /+}$ mice. A) Percent time spent in the open arms of a zero-maze apparatus in $S c n 2 a^{E /+}$ mice compared to WT at 6 weeks of age. Scn $2 a^{E /+}$ males spent significantly more time in the open arms compared to WT (WT: $15.3 \pm 2.2 \%, \operatorname{Scn} 2 a^{E /+}: 30.5 \pm 4.1 \%,{ }^{* *} \mathrm{p}=0.0023$; Student's t-test). Scn $2 a^{E /+}$ females spent significantly more time in the open arms compared to WT (WT: $22.0 \pm 2.0 \%, \operatorname{Scn} 2 a^{E /+}: 34.8 \pm$ $4.9 \%,{ }^{*} \mathrm{p}=0.0297$; Welch's t test). B) Percent time spent in the light zone of a light/dark box in $\operatorname{Scn} 2 a^{E /+}$ mice compared to WT at 7 weeks of age. Scn $2 a^{E /+}$ males spent significantly more time in the light zone compared to WT (WT: $20.9 \pm 2.0 \%, \operatorname{Scn} 2 a^{E /+}: 29.2 \pm 3.2 \%,{ }^{*} \mathrm{p}=0.0367$;

Student's t-test). $S c n 2 a^{E /+}$ females also spent significantly more time in the light zone compared to WT (WT: $21.1 \pm 1.7 \%, \operatorname{Scn} 2 a^{E /+}: 32.1 \pm 3.5 \%{ }^{*} \mathrm{p}=0.0367$; Mann-Whitney test). C) Percent time spent in the center zone of an open field apparatus in $S c n 2 a^{E /+}$ mice compared to WT at 8 weeks of age. There was not a significant difference in the amount of time spent in the center zone between $S c n 2 a^{E /+}$ and WT males ( $\mathrm{p}=0.0556$, Mann-Whitney test). However, $S c n 2 a^{E /+}$ females spent significantly more time in the center zone compared to WT (WT: $6.27 \pm 0.9 \%$, $\operatorname{Scn} 2 a^{E /+}: 10.1 \pm 1.2 \%,{ }^{*} \mathrm{p}=0.0167$; Mann-Whitney test). D) Number of marbles buried during a 30-minute trial by $S c n 2 a^{E /+}$ mice compared to WT at 6 weeks of age is displayed. $S c n 2 a^{E /+}$ males buried significantly fewer marbles compared to WT (WT: $12 \pm 1, \operatorname{Scn} 2 a^{E /+}: 5 \pm 2,{ }^{*} \mathrm{p}=0.0019$; Mann-Whitney test). Scn $2 a^{E /+}$ females also buried significantly fewer marbles compared to WT (WT: $13 \pm 2, \operatorname{Scn} 2 a^{E /+}: 2 \pm 1, * * * * p=0.0001$; Mann-Whitney test). E) Average latency to fall during an accelerating rotarod task measured on three consecutive days in $\operatorname{Scn} 2 a^{E /+}$ mice compared to WT at 9 weeks of age. Daily performance for each animal was assessed by averaging across three trials. Two-way repeated measures ANOVA comparing average latency to fall between $S c n 2 a^{E /+}$ and WT males showed significant main effects of test day $\left[F(1.511,34.76)=8.450,{ }^{* *} \mathrm{p}=0.0022\right]$ and genotype $\left[F(1,23)=10.18,{ }^{*} \mathrm{p}=0.0041\right] . S c n 2 a^{E /+}$ males took significantly longer to fall compared to WT on day 3 (WT: $121 \pm 6 \mathrm{sec}, \operatorname{Scn} 2 a^{E /+}: 152$ \pm 7 sec, $\mathrm{p}=0.0106$; Sidak's post-hoc test). Two-way repeated measures ANOVA comparing average latency to fall between $\operatorname{Scn} 2 a^{E /+}$ and WT females showed a significant main effect of test day only $\left[F(1.594,36.65)=6.646,{ }^{*} \mathrm{p}=0.0059\right]$. For panels A-D symbols represent individual 
bioRxiv preprint doi: https://doi.org/10.1101/2021.07.19.452930; this version posted July 19, 2021. The copyright holder for this preprint (which

was not certified by peer review) is the author/funder, who has granted bioRxiv a license to display the preprint in perpetuity. It is made available under aCC-BY-NC-ND 4.0 International license.

mice, horizontal lines represent mean, and error bars represent SEM. For panel E symbols and error bars represent mean \pm SEM. Males and females were analyzed separately, with $n=12-14$ per genotype for males and $n=11-15$ per genotype for females. 

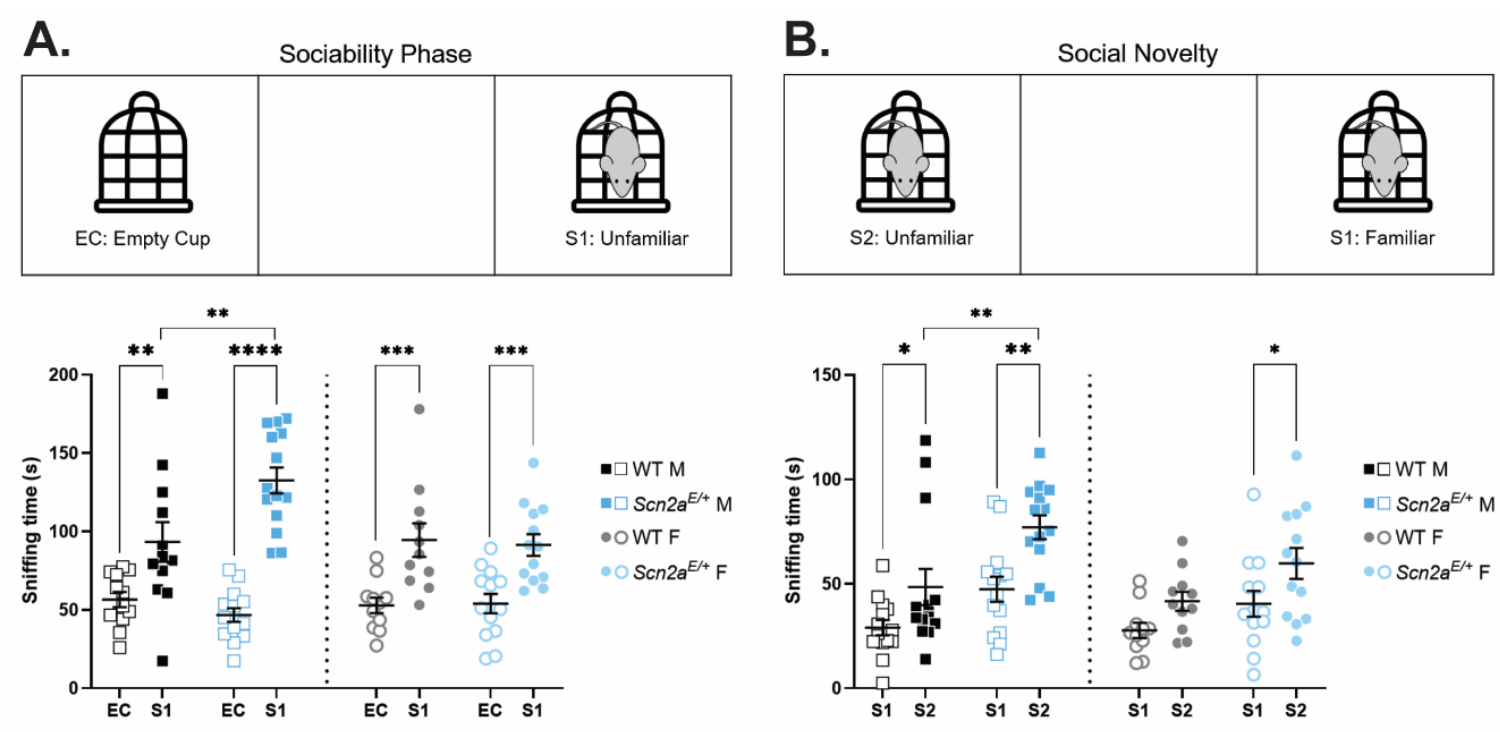

Figure 9. Altered social behavior in $\operatorname{Scn} 2 a^{E /+}$ mice. A) Sociability phase of three-chamber assay. Amount of time spent sniffing either an empty cup (EC) or unfamiliar mouse (S1) in Scn2a $a^{E /+}$ mice compared to WT at 10 weeks of age. Two-way ANOVA (using target as a within-subject variable) comparing average sniffing time between $S c n 2 a^{E /+}$ and WT males showed a significant main effect of target $[F(1,24)=57.28, \mathrm{p}<0.0001]$ and a significant interaction between target and genotype $[F(1,24)=9.198, \mathrm{p}=0.0057]$. Both $\operatorname{Scn} 2 a^{E /+}$ and WT males spent significantly more time sniffing an unfamiliar mouse compared to an empty cup $\left(\operatorname{Scn} 2 a^{E /+}: * * * * \mathrm{p}<0.0001\right.$, WT: $*^{*} \mathrm{p}=0.0100$; Sidak's post-hoc test). However, $\operatorname{Scn} 2 a^{E /+}$ males spent significantly more time sniffing an unfamiliar mouse compared to WT males (WT: $93.3 \pm 12.7 \mathrm{sec}, \operatorname{Scn} 2 a^{E /+}: 132.6 \pm 8.3$ sec, ${ }^{*} \mathrm{p}=0.0024$; Sidak's post-hoc test). Two-way ANOVA comparing average sniffing time between $\operatorname{Scn} 2 a^{E /+}$ and WT females showed a significant main effect of target only $[F(1,22)=$ $35.17, \mathrm{p}<0.0001]$. Both $S c n 2 a^{E /+}$ and WT females spent significantly more time sniffing an unfamiliar mouse compared to an empty cup $\left(\operatorname{Scn} 2 a^{E /+}: * * * \mathrm{p}<0.0007, \mathrm{WT}\right.$ : *** $<<0.0008$; Sidak's post-hoc test). B) Social novelty phase of three-chamber assay. Amount of time spent sniffing either a familiar mouse (S1) or an unfamiliar mouse (S2) in $S c n 2 a^{E /+}$ mice compared to WT at 10 weeks of age. Two-way ANOVA (using target as a within-subject variable) comparing average sniffing time between $S c n 2 a^{E /+}$ and WT males showed significant main effects of target $[F(1,26)=19.02, \mathrm{p}=0.0002]$ and genotype $[F(1,21)=11.85, \mathrm{p}=0.0020]$. Both $S c n 2 a^{E /+}$ and WT males spent significantly more time sniffing an unfamiliar mouse compared to a familiar mouse $\left(\operatorname{Scn} 2 a^{E /+}:{ }^{*} \mathrm{p}=0.0019, \mathrm{WT}:{ }^{*} \mathrm{p}=0.0432\right.$; Sidak's post-hoc test $)$. However, $\operatorname{Scn} 2 a^{E /+}$ males spent significantly more time sniffing an unfamiliar mouse compared to WT males (WT: $48.5 \pm 8.7$ sec, $\operatorname{Scn} 2 a^{E /+}: 77.1 \pm 5.7 .3 \mathrm{sec},{ }^{* *} \mathrm{p}=0.0042$; Sidak's post-hoc test). Two-way ANOVA comparing average sniffing time between $S c n 2 a^{E /+}$ and WT females also showed significant main effects of target $[F(1,22)=9.145, \mathrm{p}=0.0062]$ and genotype $[F(1,22)=6.081, \mathrm{p}=0.0219]$. However, only $\operatorname{Scn} 2 a^{E /+}$ females spent significantly more time sniffing an unfamiliar mouse compared to a familiar mouse $\left(\operatorname{Scn} 2 a^{E /+}:{ }^{*} \mathrm{p}=0.0327, \mathrm{WT}: \mathrm{p}=0.1889\right.$; Sidak's post-hoc test). Symbols represent individual mice, horizontal lines represent mean, and error bars represent SEM. Males and females were analyzed separately, with $n=12-14$ per genotype for males and $\mathrm{n}=11-13$ per genotype for females. 

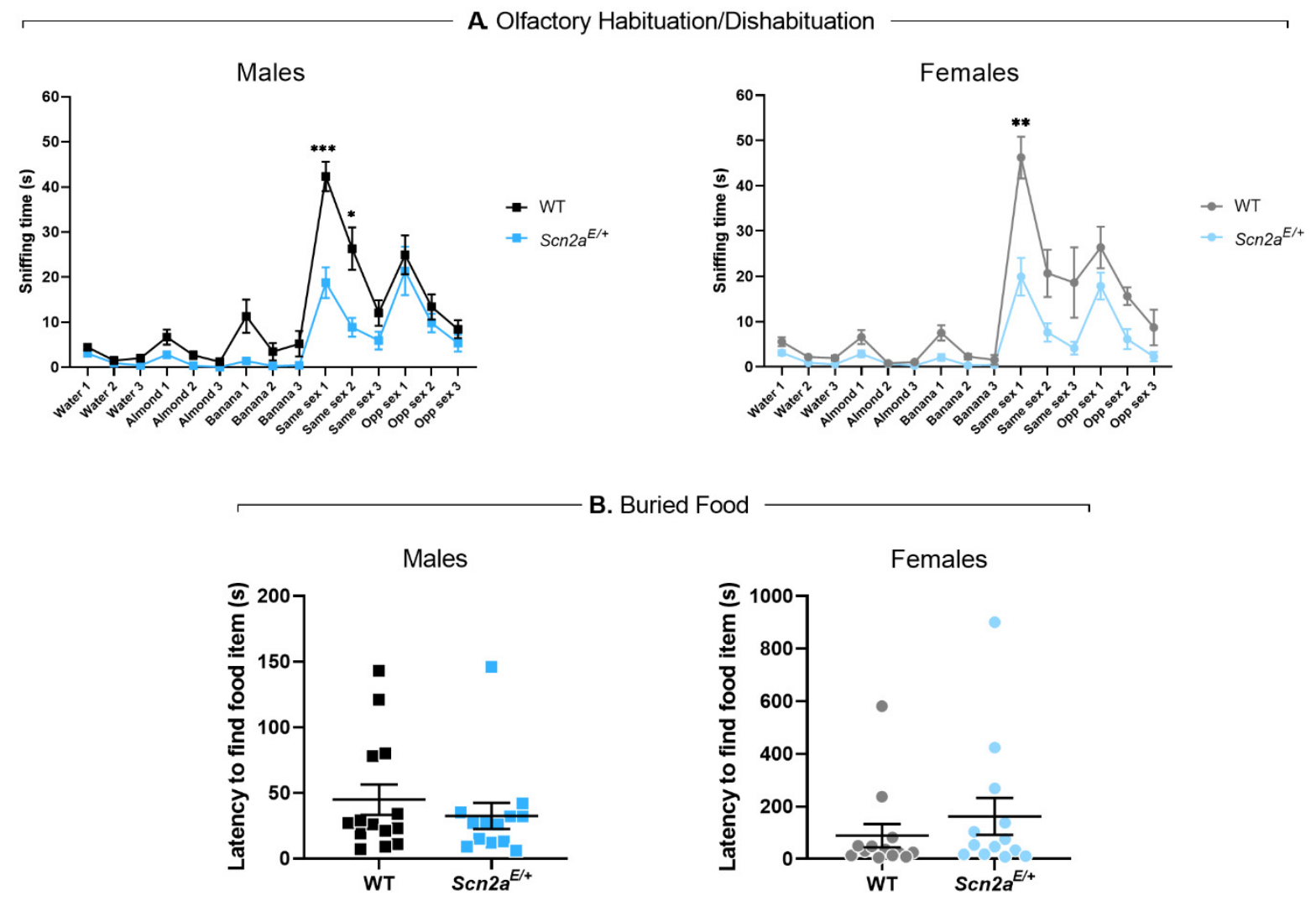

B. Buried Food

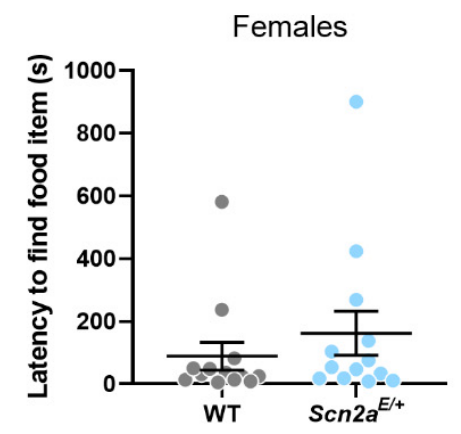

Figure 10. Lower olfactory dishabituation to social odors and intact olfactory-guided behavior in $\operatorname{Scn} 2 a^{E /+}$ mice. A) Average sniffing times during an odor habituation/dishabituation assay in $\operatorname{Scn} 2 a^{E /+}$ mice compared to WT at 11 weeks of age. Overall, olfactory discrimination in $\operatorname{Scn} 2 a^{E /+}$ males was not significantly different from WT males. However, $\operatorname{Scn} 2 a^{E /+}$ males spent significantly less time sniffing same sex urine during the first two presentations compared to WT males. During the first presentation, average sniffing time was $42.3 \pm 3.3 \mathrm{sec}$ for WT males and $18.8 \pm 3.4 \mathrm{sec}$ for $\operatorname{Scn} 2 a^{E /+}$ males (***p=0.0005, multiple t-tests). During the second presentation, average sniffing time was $26.3 \pm 8.9 \mathrm{sec}$ for WT males and $8.9 \pm 2.1 \mathrm{sec}$ for $\operatorname{Scn} 2 a^{E /+}$ males $\left({ }^{*} \mathrm{p}=0.0307\right.$, multiple t-tests). Olfactory discrimination in $\operatorname{Scn} 2 a^{E /+}$ females was also not significantly different from WT females. However, $S c n 2 a^{E /+}$ females spent significantly less time sniffing same sex urine during the first presentation compared to WT females (WT: $46.3 \pm 4.6 \mathrm{sec}, \operatorname{Scn} 2 a^{E /+}: 19.9 \pm 4.2 \mathrm{sec},{ }^{*} \mathrm{p}=0.0045$, multiple t-tests). Symbols and error bars represent mean \pm SEM. Males and females were analyzed separately, with $n=14$ per genotype for males and $n=12-13$ per genotype for females. B) Latency to find a buried food item in $\operatorname{Scn} 2 a^{E /+}$ mice compared to WT at 8 weeks of age. Latency to find a buried food item was not significantly different between $S c n 2 a^{E /+}$ and WT males (WT: $44.86 \pm 11.58 \mathrm{sec}, S c n 2 a^{E /+}: 32.46 \pm 9.95 \mathrm{sec}, \mathrm{p}$ $=0.7471$; Mann-Whitney test). Latency to find a buried food item was not significantly different between $S c n 2 a^{E /+}$ and WT females (WT: $89.00 \pm 44.31 \mathrm{sec}, \operatorname{Scn} 2 a^{E /+}: 161.7 \pm 70.02$, p = 0.2927; Mann-Whitney test). Symbols represent measured values from individual mice, horizontal lines represent mean, and error bars represent SEM. Males and females were analyzed separately, with $\mathrm{n}=13-14$ per genotype for males and $\mathrm{n}=13$ per genotype for females. 


\section{REFERENCES}

Adney SK, Millichap JJ, DeKeyser J, Abramova T, Thompson CH, George AL (2020) Functional and pharmacological evaluation of a novel SCN2A variant linked to earlyonset epilepsy. Ann Clin Transl Neurol 7:1488-1501.

Amador A et al. (2020) Modelling and treating GRIN2A developmental and epileptic encephalopathy in mice. Brain 143:2039-2057.

American Psychiatric Association (2013) Diagnostic and Statistical Manual of Mental Disorders, Fifth Edition. American Psychiatric Association. Available at: https://psychiatryonline.org/doi/book/10.1176/appi.books.9780890425596 [Accessed June 29, 2021].

Anon (2009) Troublesome variability in mouse studies. Nat Neurosci 12:1075-1075.

Barak B, Feng G (2016) Neurobiology of social behavior abnormalities in autism and Williams syndrome. Nat Neurosci 19:647-655.

Begemann A, Acuña MA, Zweier M, Vincent M, Steindl K, Bachmann-Gagescu R, Hackenberg A, Abela L, Plecko B, Kroell-Seger J, Baumer A, Yamakawa K, Inoue Y, Asadollahi R, Sticht H, Zeilhofer HU, Rauch A (2019) Further corroboration of distinct functional features in SCN2A variants causing intellectual disability or epileptic phenotypes. Mol Med 25 Available at: https://www.ncbi.nlm.nih.gov/pmc/articles/PMC6391808/ [Accessed June 4, 2021].

Ben-Shalom R, Keeshen CM, Berrios KN, An JY, Sanders SJ, Bender KJ (2017) Opposing Effects on Na V 1.2 Function Underlie Differences Between SCN2A Variants Observed in Individuals With Autism Spectrum Disorder or Infantile Seizures. Biol Psychiatry $82: 224-232$.

Berecki G, Howell KB, Deerasooriya YH, Cilio MR, Oliva MK, Kaplan D, Scheffer IE, Berkovic SF, Petrou S (2018) Dynamic action potential clamp predicts functional separation in mild familial and severe de novo forms of $S C N 2 A$ epilepsy. Proc Natl Acad Sci 115:E5516-E5525.

Bergren SK, Chen S, Galecki A, Kearney JA (2005) Genetic modifiers affecting severity of epilepsy caused by mutation of sodium channel Scn2a. Mamm Genome Off J Int Mamm Genome Soc 16:683-690.

Bessaih T, Garcia de Yebenes E, Kirkland K, Higley MJ, Buono RJ, Ferraro TN, Contreras D (2012) Quantitative trait locus on distal Chromosome 1 regulates the occurrence of spontaneous Spike Wave Discharges in DBA/2 mice. Epilepsia 53:1429-1435.

Brunklaus A, Ellis R, Reavey E, Semsarian C, Zuberi SM (2014) Genotype phenotype associations across the voltage-gated sodium channel family. J Med Genet 51:650-658. 
Burke KJ, Bender KJ (2019) Modulation of Ion Channels in the Axon: Mechanisms and Function. Front Cell Neurosci 13:221.

Calhoun JD, Hawkins NA, Zachwieja NJ, Kearney JA (2016) Cacna1g is a genetic modifier of epilepsy caused by mutation of voltage-gated sodium channel Scn2a. Epilepsia 57:e103107.

Chao H-T, Chen H, Samaco RC, Xue M, Chahrour M, Yoo J, Neul JL, Gong S, Lu H-C, Heintz N, Ekker M, Rubenstein JLR, Noebels JL, Rosenmund C, Zoghbi HY (2010) GABAergic dysfunction mediates autism-like stereotypies and Rett syndrome phenotypes. Nature 468:263-269.

Clarkson RL, Liptak AT, Gee SM, Sohal VS, Bender KJ (2017) D3 Receptors Regulate Excitability in a Unique Class of Prefrontal Pyramidal Cells. J Neurosci 37:5846-5860.

Connor JX, McCormack K, Pletsch A, Gaeta S, Ganetzky B, Chiu S-Y, Messing A (2005) Genetic modifiers of the Kv $\beta 2$-null phenotype in mice. Genes Brain Behav 4:77-88.

Crawford K, Xian J, Helbig KL, Galer PD, Parthasarathy S, Lewis-Smith D, Kaufman MC, Fitch E, Ganesan S, O’Brien M, Codoni V, Ellis CA, Conway LJ, Taylor D, Krause R, Helbig I (2021) Computational analysis of 10,860 phenotypic annotations in individuals with SCN2A -related disorders. Genet Med:1-10.

DeKeyser J-M, Thompson CH, George AL (2021) Cryptic prokaryotic promoters explain instability of recombinant neuronal sodium channels in bacteria. J Biol Chem 296:100298.

Dudev T, Lim C (2014) Ion Selectivity Strategies of Sodium Channel Selectivity Filters. Acc Chem Res 47:3580-3587.

Favre I, Moczydlowski E, Schild L (1996) On the structural basis for ionic selectivity among $\mathrm{Na}+, \mathrm{K}+$, and $\mathrm{Ca} 2+$ in the voltage-gated sodium channel. Biophys J 71:3110-3125.

Ferland RJ (2017) The Repeated Flurothyl Seizure Model in Mice. Bio-Protoc 7 Available at: https://www.ncbi.nlm.nih.gov/pmc/articles/PMC5524139/ [Accessed June 16, 2020].

Filipis L, Canepari M (2021) Optical measurement of physiological sodium currents in the axon initial segment. J Physiol 599:49-66.

Fozzard HA, Lipkind GM (2010) The Tetrodotoxin Binding Site Is within the Outer Vestibule of the Sodium Channel. Mar Drugs 8:219-234.

Frankel WN, Mahaffey CL, McGarr TC, Beyer BJ, Letts VA (2014) Unraveling Genetic Modifiers in the Gria4 Mouse Model of Absence Epilepsy. PLoS Genet 10 Available at: https://www.ncbi.nlm.nih.gov/pmc/articles/PMC4091709/ [Accessed May 25, 2020]. 
Gangisetty O, Reddy DS (2010) Neurosteroid withdrawal regulates GABA-A receptor $\alpha 4-$ subunit expression and seizure susceptibility by activation of progesterone receptorindependent early growth response factor-3 pathway. Neuroscience 170:865-880.

Gazina EV, Richards KL, Mokhtar MBC, Thomas EA, Reid CA, Petrou S (2010) Differential expression of exon 5 splice variants of sodium channel $\alpha$ subunit mRNAs in the developing mouse brain. Neuroscience 166:195-200.

Geiger JRP, Jonas P (2000) Dynamic Control of Presynaptic Ca2+ Inflow by Fast-Inactivating $\mathrm{K}+$ Channels in Hippocampal Mossy Fiber Boutons. Neuron 28:927-939.

Gong B, Rhodes KJ, Bekele-Arcuri Z, Trimmer JS (1999) Type I and type II Na+ channel $\alpha$ subunit polypeptides exhibit distinct spatial and temporal patterning, and association with auxiliary subunits in rat brain. J Comp Neurol 412:342-352.

Gur Barzilai M, Reitzel AM, Kraus JEM, Gordon D, Technau U, Gurevitz M, Moran Y (2012) Convergent Evolution of Sodium Ion Selectivity in Metazoan Neuronal Signaling. Cell Rep 2:242-248.

Hanemaaijer NA, Popovic MA, Wilders X, Grasman S, Pavón Arocas O, Kole MH (2020) Ca2+ entry through $\mathrm{NaV}$ channels generates submillisecond axonal $\mathrm{Ca} 2+$ signaling. eLife 9:e54566.

Hawkins NA, Zachwieja NJ, Miller AR, Anderson LL, Kearney JA (2016) Fine Mapping of a Dravet Syndrome Modifier Locus on Mouse Chromosome 5 and Candidate Gene Analysis by RNA-Seq. PLoS Genet 12 Available at:

https://www.ncbi.nlm.nih.gov/pmc/articles/PMC5074504/ [Accessed December 5, 2020].

Heinemann S, Heinrich T, Stühmer W, Imoto K, Numa S (1992) Calcium Channel Characteristics Conferred on the Sodium Channel by Single Mutations. Nature 356:441443.

Hu W, Tian C, Li T, Yang M, Hou H, Shu Y (2009) Distinct contributions of Na v 1.6 and Na v 1.2 in action potential initiation and backpropagation. Nat Neurosci 12:996-1002.

Indumathy J, Pruitt A, Gautier NM, Crane K, Glasscock E (2021) Kv1.1 deficiency alters repetitive and social behaviors in mice and rescues autistic-like behaviors due to Scn2a haploinsufficiency. Brain Behav 11 Available at: https://www.ncbi.nlm.nih.gov/pmc/articles/PMC8035482/ [Accessed May 4, 2021].

Joshi S, Kapur J (2019) Neurosteroid regulation of GABAA receptors: A role in catamenial epilepsy. Brain Res 1703:31-40.

Kawai T, Hashimoto M, Eguchi N, Nishino JM, Jinno Y, Mori-Kreiner R, Aspåker M, Chiba D, Ohtsuka Y, Kawanabe A, Nishino AS, Okamura Y (2021) Heterologous functional expression of ascidian Nav1 channels and close relationship with the evolutionary ancestor of vertebrate Nav channels. J Biol Chem 296 Available at: https://www.jbc.org/article/S0021-9258(21)00576-7/abstract [Accessed July 2, 2021]. 
Kehrl JM, Sahaya K, Dalton HM, Charbeneau RA, Kohut KT, Gilbert K, Pelz MC, Parent J, Neubig RR (2014) Gain-of-function mutation in Gnao1: A murine model of epileptiform encephalopathy (EIEE17)? Mamm Genome 25:202-210.

Kight KE, McCarthy MM (2014) Using sex differences in the developing brain to identify nodes of influence for seizure susceptibility and epileptogenesis. Neurobiol Dis 72:136-143.

Kim J, Ghosh S, Liu H, Tateyama M, Kass RS, Pitt GS (2004) Calmodulin Mediates Ca2+ Sensitivity of Sodium Channels*. J Biol Chem 279:45004-45012.

Léna I, Mantegazza M (2019) NaV1.2 haploinsufficiency in Scn2a knock-out mice causes an autistic-like phenotype attenuated with age. Sci Rep 9:12886.

Li J, Leverton LK, Naganatanahalli LM, Christian-Hinman CA (2020) Seizure burden fluctuates with the female reproductive cycle in a mouse model of chronic temporal lobe epilepsy. Exp Neurol 334:113492.

Lipkin AM, Cunniff MM, Spratt PWE, Lemke SM, Bender KJ (2021) Functional Microstructure of CaV-Mediated Calcium Signaling in the Axon Initial Segment. J Neurosci 41:37643776.

Lorincz A, Nusser Z (2010) Molecular Identity of Dendritic Voltage-Gated Sodium Channels. Science 328:906-909.

Martin MS, Tang B, Papale LA, Yu FH, Catterall WA, Escayg A (2007) The voltage-gated sodium channel Scn8a is a genetic modifier of severe myoclonic epilepsy of infancy. Hum Mol Genet 16:2892-2899.

Mejias R, Adamczyk A, Anggono V, Niranjan T, Thomas GM, Sharma K, Skinner C, Schwartz CE, Stevenson RE, Fallin MD, Kaufmann W, Pletnikov M, Valle D, Huganir RL, Wang $\mathrm{T}$ (2011) Gain-of-function glutamate receptor interacting protein 1 variants alter GluA2 recycling and surface distribution in patients with autism. Proc Natl Acad Sci U S A 108:4920-4925.

Meves H, Vogel W (1973) Calcium inward currents in internally perfused giant axons. J Physiol 235:225-265.

Miller AR, Hawkins NA, McCollom CE, Kearney JA (2014) Mapping genetic modifiers of survival in a mouse model of Dravet syndrome. Genes Brain Behav 13:163-172.

Mishra V, Karumuri BK, Gautier NM, Liu R, Hutson TN, Vanhoof-Villalba SL, Vlachos I, Iasemidis L, Glasscock E (2017) Scn2a deletion improves survival and brain-heart dynamics in the Kcna1-null mouse model of sudden unexpected death in epilepsy (SUDEP). Hum Mol Genet 26:2091-2103.

Mistry AM, Thompson CH, Miller AR, Vanoye CG, George ALJ, Kearney JA (2014) Strainand age-dependent hippocampal neuron sodium currents correlate with epilepsy severity in Dravet syndrome mice. Neurobiol Dis 65:1-11. 
Naylor CE, Bagnéris C, DeCaen PG, Sula A, Scaglione A, Clapham DE, Wallace B (2016) Molecular basis of ion permeability in a voltage-gated sodium channel. EMBO J 35:820 830.

Ogiwara I, Ito K, Sawaishi Y, Osaka H, Mazaki E, Inoue I, Montal M, Hashikawa T, Shike T, Fujiwara T, Inoue Y, Kaneda M, Yamakawa K (2009) De novo mutations of voltagegated sodium channel $\alpha$ II gene SCN2A in intractable epilepsies. Neurology 73:10461053.

Ogiwara I, Miyamoto H, Tatsukawa T, Yamagata T, Nakayama T, Atapour N, Miura E, Mazaki E, Ernst SJ, Cao D, Ohtani H, Itohara S, Yanagawa Y, Montal M, Yuzaki M, Inoue Y, Hensch TK, Noebels JL, Yamakawa K (2018) Nav1.2 haplodeficiency in excitatory neurons causes absence-like seizures in mice. Commun Biol 1:1-16.

Perihan C, Bicer A, Bocanegra J (2021) Assessment and Treatment of Anxiety in Children with Autism Spectrum Disorder in School Settings: A Systematic Review and Meta-Analysis. School Ment Health Available at: https://doi.org/10.1007/s12310-021-09461-7 [Accessed June 29, 2021].

Planells-Cases R, Caprini M, Zhang J, Rockenstein EM, Rivera RR, Murre C, Masliah E, Montal M (2000) Neuronal death and perinatal lethality in voltage-gated sodium channel alpha(II)-deficient mice. Biophys J 78:2878-2891.

Ritzau-Jost A, Delvendahl I, Rings A, Byczkowicz N, Harada H, Shigemoto R, Hirrlinger J, Eilers J, Hallermann S (2014) Ultrafast Action Potentials Mediate Kilohertz Signaling at a Central Synapse. Neuron 84:152-163.

Rowan MJM, Tranquil E, Christie JM (2014) Distinct Kv Channel Subtypes Contribute to Differences in Spike Signaling Properties in the Axon Initial Segment and Presynaptic Boutons of Cerebellar Interneurons. J Neurosci 34:6611-6623.

Sah M, Shore AN, Petri S, Kanber A, Yang M, Weston MC, Frankel WN (2020) Altered excitatory transmission onto hippocampal interneurons in the IQSEC2 mouse model of X-linked neurodevelopmental disease. Neurobiol Dis 137:104758.

Sanders SJ et al. (2012) De novo mutations revealed by whole exome sequencing are strongly associated with autism. Nature 485:237-241.

Sanders SJ et al. (2018) Progress in Understanding and Treating SCN2A-Mediated Disorders. Trends Neurosci 41:442-456.

Saré RM, Lemons A, Smith CB (2021) Behavior Testing in Rodents: Highlighting Potential Confounds Affecting Variability and Reproducibility. Brain Sci 11:522.

Scalmani P, Rusconi R, Armatura E, Zara F, Avanzini G, Franceschetti S, Mantegazza M (2006) Effects in Neocortical Neurons of Mutations of the Nav1.2 Na+ Channel causing Benign Familial Neonatal-Infantile Seizures. J Neurosci 26:10100-10109. 
Scharfman HE, Goodman JH, Rigoulot M-A, Berger RE, Walling SG, Mercurio TC, Stormes K, Maclusky NJ (2005) Seizure susceptibility in intact and ovariectomized female rats treated with the convulsant pilocarpine. Exp Neurol 196:73-86.

Schlief T, Schönherr R, Imoto K, Heinemann SH (1996) Pore properties of rat brain II sodium channels mutated in the selectivity filter domain. Eur Biophys J EBJ 25:75-91.

Shepherd JK, Grewal SS, Fletcher A, Bill DJ, Dourish CT (1994) Behavioural and pharmacological characterisation of the elevated "zero-maze" as an animal model of anxiety. Psychopharmacology (Berl) 116:56-64.

Shi X, Yasumoto S, Kurahashi H, Nakagawa E, Fukasawa T, Uchiya S, Hirose S (2012) Clinical spectrum of SCN2A mutations. Brain Dev 34:541-545.

Silverman JL, Yang M, Lord C, Crawley JN (2010) Behavioural phenotyping assays for mouse models of autism. Nat Rev Neurosci 11:490-502.

Spratt PWE, Ben-Shalom R, Keeshen CM, Burke KJ, Clarkson RL, Sanders SJ, Bender KJ (2019) The Autism-Associated Gene Scn2a Contributes to Dendritic Excitability and Synaptic Function in the Prefrontal Cortex. Neuron 103:673-685.e5.

Spratt PWE, Ben-Shalom R, Sahagun A, Keeshen CM, Sanders SJ, Bender KJ (2021) Paradoxical hyperexcitability from NaV1.2 sodium channel loss in neocortical pyramidal cells. bioRxiv:2021.02.02.429423.

Stanley EF (2016) The Nanophysiology of Fast Transmitter Release. Trends Neurosci 39:183197.

Stephens RF, Guan W, Zhorov BS, Spafford JD (2015) Selectivity filters and cysteine-rich extracellular loops in voltage-gated sodium, calcium, and NALCN channels. Front Physiol 6 Available at:

https://www.frontiersin.org/articles/10.3389/fphys.2015.00153/full\#B82 [Accessed July 2, 2021].

Sundaram SK, Chugani HT, Tiwari VN, Huq AM (2013) SCN2A mutation is associated with infantile spasms and bitemporal glucose hypometabolism. Pediatr Neurol 49 Available at: https://www.ncbi.nlm.nih.gov/pmc/articles/PMC3868437/ [Accessed October 9, 2018].

Swain SM, Sahoo N, Dennhardt S, Schönherr R, Heinemann SH (2015) Ca(2+)/calmodulin regulates Kv $\beta 1.1$-mediated inactivation of voltage-gated $K(+)$ channels. Sci Rep 5:15509.

Tatsukawa T, Raveau M, Ogiwara I, Hattori S, Miyamoto H, Mazaki E, Itohara S, Miyakawa T, Montal M, Yamakawa K (2019) Scn2a haploinsufficient mice display a spectrum of phenotypes affecting anxiety, sociability, memory flexibility and ampakine CX516 rescues their hyperactivity. Mol Autism 10:15.

Terlau H, Heinemann SH, Stühmer W, Pusch M, Conti F, Imoto K, Numa S (1991) Mapping the site of block by tetrodotoxin and saxitoxin of sodium channel II. FEBS Lett 293:93-96. 
Thompson CH, Ben-Shalom R, Bender KJ, George AL (2020) Alternative splicing potentiates dysfunction of early-onset epileptic encephalopathy SCN2A variants. J Gen Physiol 152:e201912442.

Thompson CH, Hawkins NA, Kearney JA, George ALJ (2017) CaMKII modulates sodium current in neurons from epileptic Scn2a mutant mice. Proc Natl Acad Sci U S A 114:1696-1701.

Thompson CH, Kahlig KM, George ALJ (2011) SCN1A splice variants exhibit divergent sensitivity to commonly used antiepileptic drugs. Epilepsia 52:1000-1009.

Thompson CH, Porter JC, Kahlig KM, Daniels MA, George ALJ (2012) Nontruncating SCN1A mutations associated with severe myoclonic epilepsy of infancy impair cell surface expression. J Biol Chem 287:42001-42008.

Vacher H, Mohapatra DP, Trimmer JS (2008) Localization and Targeting of Voltage-Dependent Ion Channels in Mammalian Central Neurons. Physiol Rev 88:1407-1447.

van Steensel FJA, Bögels SM, Perrin S (2011) Anxiety Disorders in Children and Adolescents with Autistic Spectrum Disorders: A Meta-Analysis. Clin Child Fam Psychol Rev $14: 302-317$.

Wen H, Levitan IB (2002) Calmodulin Is an Auxiliary Subunit of KCNQ2/3 Potassium Channels. J Neurosci 22:7991-8001.

Wolff $\mathrm{M}$ et al. (2017) Genetic and phenotypic heterogeneity suggest therapeutic implications in SCN2A-related disorders. Brain 140:1316-1336.

Wolff M, Brunklaus A, Zuberi SM (2019) Phenotypic spectrum and genetics of SCN2A-related disorders, treatment options, and outcomes in epilepsy and beyond. Epilepsia 60:S59S67.

Woolley CS (2000) Estradiol Facilitates Kainic Acid-Induced, but not Flurothyl-Induced, Behavioral Seizure Activity in Adult Female Rats. Epilepsia 41:510-515.

Yang M, Crawley JN (2010) Simple Behavioral Assessment of Mouse Olfaction. :14.

Zakon HH (2012) Adaptive evolution of voltage-gated sodium channels: The first 800 million years. Proc Natl Acad Sci U S A 109:10619-10625.

Zhou W, Chung I, Liu Z, Goldin AL, Dong K (2004) A Voltage-Gated Calcium-Selective Channel Encoded by a Sodium Channel-like Gene. Neuron 42:101-112.

Zhu Y, Li D, Huang H (2020) Activity and Cytosolic Na+ Regulate Synaptic Vesicle Endocytosis. J Neurosci 40:6112-6120. 